\title{
Elevated temperature performance of restrained stainless steel beams
}

\author{
A. Pournaghshband ${ }^{\text {a }}$, S. Afshan ${ }^{b^{*}}$, M. Theofanous ${ }^{c}$ \\ ${ }^{\text {a }}$ University of West London, London, UK \\ ${ }^{\mathrm{b}}$ University of Southampton, Southampton, UK \\ ${ }^{c}$ Birmingham University, Birmingham, UK
}

Corresponding author Email: $\underline{\text { S.Afshan@ } @ \text { soton.ac.uk }}$

\section{Abstract}

This paper reports the results of a numerical investigation into the response of axially restrained austenitic stainless steel beams in fire, where in addition to the degradation of strength and stiffness at elevated temperatures, the influence of thermally induced stresses, are also included. The finite element (FE) programme ABAQUS has been used to model austenitic stainless steel welded I-section beams of different axial end restraint stiffness subjected to fire. The FE models are firstly validated against a selection of literature test data, which are shown to accurately capture the effects of restrained thermal deformations with a high degree of accuracy, and then used to perform parametric studies to further explore the structural behaviour in fire. A simplified analytical model for predicting the restraint axial force-temperature response is presented and validated against the numerically obtained results. The numerical models and the simplified analytical model allow the influence of frame continuity to be explicitly considered in design of stainless steel members in fire to quantify the required strength and ductility demands on connections for catenary action to develop. Comparisons with carbon steel beams demonstrate that while austenitic stainless steel beams show similar stages of behaviour in fire, they are capable of withstanding higher temperatures prior to the onset of catenary action, while developing similar levels of maximum tensile catenary force to carbon steel beams, despite the higher thermal expansion of the material.

Keywords: Catenary action, Design, Numerical modelling, Restraint forces, Stainless steel beam

\section{Introduction}

Stainless steel members are often used in buildings in load-bearing applications. Due to their superior behaviour in terms of strength and stiffness retention at elevated temperatures compared to carbon steel, stainless steel members are often used unprotected, thus reducing overall building costs. The performance of unprotected stainless steel structures in fire has been studied by a number of researchers over the past years. At material level, the elevated temperature behaviour of stainless steel has been studied extensively by means of isothermal and anisothermal tests [13 ], where it has been shown that stainless steel generally offers better retention of strength and stiffness than carbon steel, especially at the temperature range of $500-800{ }^{\circ} \mathrm{C}$, owing to the beneficial effects of the alloying elements. At member level, experimental and numerical modelling studies of the response of unprotected stainless steel structural members exposed to fire have been performed [4-8], which provided a valuable insight into the effects of instability, temperature gradients and full cross-sectional behaviour on fire performance. However, most previous studies have been mainly focused on understanding the fire performance of individual elements such as statically determinate columns and beams, leading to the development of component based fire design guidelines such as those in EN 1993-1-2 [9]. 
In structural frames, due to continuity, each structural member is restrained axially and/or rotationally by adjacent members. Therefore, in addition to the degradation of material strength and stiffness at elevated temperatures, the effects of thermally induced stresses on the structural response have to be considered. The response of restrained structural members in fire is accompanied by large deflections due to the restrained thermal expansion and thermal bowing effects. In the case of flexural members, i.e. beams, these large deflections enable the development of catenary action which is the ability of the beam to support itself predominantly by means of axial tension rather than flexure. Since resistance by catenary action is related to the large deflections undergone in fire, rather than the strength of the material at elevated temperatures, a beam with reducing material strength at high temperatures can still continue to support the applied loading through undergoing further deflection. The development of catenary action in beams was identified as one of the main factors contributing to the reserve of strength of the composite steelconcrete frames in the Cardington fire tests [10]. The use of catenary action as a load carrying mechanism in fire is of particular interest for the case of stainless steel beams in fire, as they are often used without fire protection, and, in addition, the high ductility and substantial strain hardening of the material lends itself to consideration of load carrying mechanisms such as catenary action which is triggered by large deflections.

The response of restrained carbon steel beams in fire has been studied both experimentally and numerically and performance based design approaches have been proposed by a number of researchers. Liu et al. [11] carried out full-scale fire tests on partially protected axially and rotationally restrained steel beams, which demonstrated the development of catenary action as a mechanism to prevent beam deflections from runaway (i.e. very large deflections at high temperatures due to diminished beam bending stiffness) at very high temperatures. Yin and Wang [12] conducted a numerical modelling study to replicate Liu et al.'s tests and investigated the influence of varying levels of axial and rotational end restraint stiffness on the fire performance and catenary action through a numerical parametric study. Wang and Yin [13] proposed a simplified calculation method for predicting the large deflection behaviour of restrained steel beams under fire conditions. The method assumes an initial deflection profile, which depends on the loading condition, end rotational restraint and temperature distribution in the cross-section, and the internal fire-induced forces are determined by differentiating the deflection profile and applying relevant boundary conditions. Dwaikat and Kodur [14] proposed a performance based approach that is based on compatibility and equilibrium principles for assessing the fire resistance of restrained beams, and considered the influence of a number of factors such as end restraints, thermal gradient, connection type, load level, beam geometry and failure criteria.

The fire response of restrained stainless steel beams has however attracted little attention to date. The different mechanical and thermal properties of stainless steel compared with carbon steel, notably its higher strength and stiffness, higher thermal expansion and lower thermal conductivity, require that the combined effects of these factors are systematically accounted for in the analysis and design of stainless steel structures in fire. Hence, to obtain a better understanding of the response of stainless steel structures in fire, the behaviour of axially restrained austenitic stainless steel beams exposed to uniform temperature distribution across the cross-section is investigated herein. Firstly, a theoretical description of the response of axially restrained steel beams in fire is given in Section 2. This is followed by a numerical modelling investigation presented in Section 
3, where finite element models of axially restrained steel beams are presented and validated against data from physical tests reported in the literature. In Section 4, the validated numerical models are employed for parametric studies to investigate the fire performance of axially restrained austenitic stainless steel beams; the results are then analysed and used for the development and validation of the simplified analytical model presented in Section 5.

\section{Fire behaviour of restrained steel beams}

Steel beams forming part of a complete structural frame are restrained by the adjacent structure either axially, rotationally or both, and therefore, the behaviour of a restrained beam in fire is considerably different from that of an isolated beam without restraints. Figure 1 depicts the stages of behaviour for the general case of a restrained steel beam with axial and rotational end restraints subjected to a standard fire with no decay phase, and giving rise to a non-uniform temperature distribution across the beam section. When exposed to fire, the beam develops significant fire induced internal actions, i.e. axial force (from restrained axial displacement) and bending moment (from restrained rotational displacement), and large deflections due to the effect of restraints and deterioration of mechanical properties with increasing temperature. Assuming that the beam is laterally restrained (i.e. no lateral torsional buckling) and is made of a compact cross-section (i.e. no local buckling of the cross-section prior to yielding), there are three typical stages of behaviour as described hereafter.

- In Stage I, the response is predominantly elastic. The axial restraint partially prevents the thermal expansion of the beam, thereby leading to the development of a compressive axial force accompanied by an increase in beam length due to axial expansion. Similarly, the rotational restraint in conjunction with the thermal curvature resulting from the temperature gradient in the cross-section of the beam, leads to the development of hogging bending moment at the beam ends accompanied by thermally induced curving and a corresponding increase in beam deflections. The fire induced internal forces and deflections continue to increase with temperature until yielding of the most highly stressed beam cross-section occurs.

- In Stage II, the response is elasto-plastic. As plasticity spreads throughout the beam section, the compressive axial force and the hogging bending moment will start to be relieved, which is accompanied by an increase in the beam deflection and a reduction in the axial expansion. This continues until the internal forces return back to zero.

- In Stage III, the beam enters the catenary phase where the deflection in the beam becomes sufficiently large for the load bearing mechanism to change from flexure to catenary action until failure occurs by tensile fracture of the beam or the connection.

\section{Validation of numerical models}

A numerical modelling study was performed to examine the large deflection behaviour of axially restrained stainless steel beams at elevated temperatures. The finite element (FE) software package ABAQUS [15], which has been successfully used in other similar studies to simulate the response of steel structures in fire e.g. in $[8,16]$ and stainless steel simply-supported beams and columns e.g. in [5-6, 8], was employed. In order to establish the validity of the developed FE models, comparisons were made with the results of fire tests conducted by Liu et al. [11] on restrained carbon steel beams. The validated FE models were subsequently used to investigate the 
behaviour of restrained stainless steel beams in fire. Detailed descriptions of the developed FE models along with the validation results are presented hereafter.

\subsection{Summary of literature test results}

All fire tests on stainless steel beams reported in the literature have been performed on simply supported beams without axial restraint. Hence, the results of the fire tests on restrained carbon steel beams carried out by Liu et al. [11] were used to validate the numerical models developed herein. The tests were carried out in the Fire Research Laboratory at the University of Manchester [11], where a total of fifteen axially and rotationally restrained beams were tested. The beams were UB $178 \times 102 \times 19$ in Grade S275 and were restrained between two S275 UC $152 \times 152 \times 30$ columns in the form of a 'rugby goalpost' frame, which was arranged in a reaction frame placed in a furnace box as shown in Figure 2.

The axial restraint stiffness provided by the UC $152 \times 152 \times 30$ columns to the beam ends was 8 $\mathrm{kN} / \mathrm{mm}$ ( $2 \%$ of the beam axial stiffness at room temperature). Additional axial restraint was applied at the beam ends by means of struts which spanned between the goalpost columns and the reaction frame columns to achieve different degrees of axial restraint stiffness equal to $35 \mathrm{kN} / \mathrm{mm}$ and $62 \mathrm{kN} / \mathrm{mm}$ (9\% and 16\% of the beam axial stiffness at room temperature, respectively). Two types of beam-to-column connections, namely flush end-plate and double angle web-cleat, were employed to examine the effect of connection type on the large deflection behaviour of the tested beams. The beams were loaded in the four-point bending configuration where two transverse loads, of magnitude $P$, were applied at a distance of $0.6 \mathrm{~m}$ from each beam ends. Table 1 presents a summary of these tests, where $k_{A}$ is the employed axial restraint stiffness, $k_{R}$ is the employed rotational restraint stiffness, $P$ is the applied point load per loading jack and the load level is defined as the ratio of the applied maximum bending moment to the plastic bending moment capacity of the beam at ambient temperature, assuming a design yield strength of $275 \mathrm{MPa}$.

All fire tests were performed anisothermally, where the loads were applied at room temperature and then kept at a constant level, while the furnace temperature was set to increase following the ISO834 standard fire curve, as shown in Figure 3. During the application of fire, the web and the bottom flange of the tested beams were unprotected, while the top flange was insulated using a $15 \mathrm{~mm}$ thick ceramic fibre blanket. The goalpost frame columns were also fire protected. Typical measured specimen temperature-time profiles of the web, top flange and bottom flange at the midspan section of the beams are depicted in Figure 3 [11].

\subsection{Development of numerical models}

The modelling procedure for the anisothermal fire tests involved development of a sequentially coupled thermal-stress analysis. Firstly, a nonlinear thermal analysis was conducted to compute the temperature development in the beams which was followed by a geometrically and materially nonlinear stress analysis to determine the structural response under the application of load and temperature.

\subsubsection{Thermal analysis model}

The measured furnace temperature-time curve presented in Figure 3 was applied to the exposed surfaces of the beam specimens in the heat transfer model, and temperature development was simulated through the convection, radiation and conduction heat transfer mechanisms. To simulate the experimental conditions, where the top flange was protected, only the web and the 
bottom flange of the beam specimens were exposed to fire, and temperature development in the top flange was modelled through conduction only. Radiation was modelled as surface radiation by means of the *SRADIATE command in ABAQUS with the emissivity coefficient taken as 0.7 from EN 1993-1-2 [9]. Convection was modelled as a film condition using the *SFILM command in ABAQUS with the convective heat transfer coefficient taken as $25 \mathrm{~W} / \mathrm{m}^{2} \mathrm{~K}$ as specified in EN 1993-1-2 [9]. Other thermal properties including specific heat, thermal conductivity and thermal expansion provided in EN 1993-1-2 [9] were adopted. The beams were modeled with DS4 shell elemnts with a uniform mesh size of $10 \mathrm{~mm} \times 10 \mathrm{~mm}$, which from the mesh sensitivity analysis gave the best compromise between accuracy and computational efficiency. The temperature-time curves from the thermal analysis model were subsequently applied to the stress analysis model to simulate the structural response of restrained steel beams when subjected to temperature increase.

\subsubsection{Stress analysis model}

In order to simulate the finite translational and rotational end restraint conditions of the tested beams in the stress analysis model, a structural model with axial and rotational springs as shown in Figure 4 was employed. Axial and rotational springs were modelled by means of SPRING elements in ABAQUS using the *Element, type=Spring 2 and $*$ Element, type=Spring 1 commands for the axial and rotational springs, respectively. Both spring types were assumed to be linear elastic with axial stiffness $k_{A}$ and rotational stiffness $k_{R}$ set equal to the experimentally measured axial and rotational restraint stiffness values reported in Table 1.

\subsubsection{Geometric imperfections and residual stresses}

Initial local and global geometric imperfections in the form of the lowest global and local buckling modes were obtained from an eigenvalue buckling prediction analysis and assigned to the numerical models as the starting geometry. The global imperfection amplitude was taken as $L / 1000$, where $L$ is the beam length, in accordance with the permitted out-of-straightness tolerance in EN 1090-2 [17], while the local imperfection amplitude was taken as that predicted from the modified Dawson and Walker model [18]. Residual stresses in hot-rolled steel sections are the self-equilibrating internal stresses that exist in an unloaded member as a result of the differential cooling after the forming process. The residual stress pattern recommended in [19] for crosssections with height $(H)$-to-width $(B)$ ratio greater than 1.2, as shown in Figure 5, was applied to the FE models developed herein, where the peak compressive residual stresses and the tensile residual stresses designated as positive and negative, respectively were both set to $0.3 f_{y}^{*}$, where $f_{y} *=235 \mathrm{MPa}$ is taken as the reference value as recommended in [19]. The four-node doubly curved shell element with reduced integration S4R, which is compatible with the DS4 elements, with the same mesh element size as for the thermal models $(10 \mathrm{~mm} \times 10 \mathrm{~mm})$, was used to discretise the FE models. The models included web stiffeners with the same arrangement as that in the physical experiments in order to avoid premature local bearing failure of the web [11].

\subsubsection{Material modelling}

The elevated temperature stress-strain relationship for carbon steel provided in EN 1993-1-2 [9], along with the measured room temperature material properties from the experimental programme [11] and the elevated temperature strength and stiffness reduction factors set out in EN 1993-1-2 [9], were utilised to construct a series of temperature dependent stress-strain curves. In ABAQUS, the material behaviour was modelled as elastic-plastic with a von Mises yield criterion and 
isotropic hardening with the input stress-strain curves included in the form of multi-linear true stress and logarithmic plastic strain responses; these were obtained from the constructed engineering stress-strain relationships.

\subsubsection{Boundary conditions and analysis steps}

To simulate the boundary conditions of the experimental set up, the beam end cross-sections were first connected to concentric reference points defined at each beam end through * Rigid Body coupling so that the degrees of freedom of all nodes at beam end cross-section were constrained to the degrees of freedom of their corresponding reference point. The boundary conditions were then assigned to these reference point, RP-1 and RP-2 in Figure 6, where all degrees of freedom were restrained apart from the longitudinal translation and rotation about the cross-section major axis ( $U_{Z}=F R E E$ and $U_{X}=F R E E$ ) at both ends. The axial and rotational springs, simulating the axial and rotational restraints applied in the tests, were also assigned to these reference points. The transverse loads were applied to the model at $0.6 \mathrm{~m}$ from each beam end through reference points RP-3 and RP-4, which were defined using * Kinematic coupling in the vertical direction, as shown in Figure 6. The models were laterally restrained to avoid lateral-torsional buckling.

The geometrically and materially nonlinear stress analysis was carried out in two steps, where in Step 1, the transverse loads $P$ were applied at room temperature through reference points RP-3 and RP-4 and maintained constant throughout Step 2, where the temperature was increased following the temperature-time relationships stored from the nonlinear thermal analysis model. To measure the restraint axial force and bending moment induced by the restrained axial and rotational displacements at the beam ends, the axial and rotational springs were activated at the start of step 2. The general static solver in ABAQUS was used for both Steps 1 and 2.

\subsection{Validation results}

The sequentially coupled thermal-stress analysis models described in Section 3.2 were validated against the 15 axially and rotationally restrained steel beam tests presented in Table 1. Figures 79 compare axial force-temperature and deflection-temperature curves obtained from the FE models with the test results for the beams with flush end-plate connection and under $8 \mathrm{kN} / \mathrm{mm}$, $35 \mathrm{kN} / \mathrm{mm}$ and $62 \mathrm{kN} / \mathrm{mm}$ axial restraints, respectively. The same tests were also replicated numerically by Yin and Wang [12] and Liu and Davies [20], the results of which are also depicted in Figures 7-9, where it is shown that comparable results are obtained by all numerical models.

The FE models developed herein were capable of accurately replicating the measured temperature-axial force and temperature-deflection experimental responses. The axial force and deflection characteristics typical of axially and rotationally restrained beams in fire as described in Section 2 and exhibited by the tested beams were accurately captured by the FE models. The unavoidable discrepancies that exist between the test and FE results are due to the variations in the actual and simulated temperature distributions and the generalised elevated temperature stressstrain relationships assumed.

The failure modes of the tested steel beams were reported by Liu et al [11] to mainly include (1) formation of two plastic hinges under the loading points and two others close to end supports as well as (2) local buckling of the bottom flange close to the end supports. The deformed shapes obtained by the FE models closely replicated the test observed failure modes as shown in Figure 10. Following successful validation, the developed finite element models were employed to 
perform parametric numerical investigation on axially restrained stainless steel beams in fire detailed descriptions of which are presented in the following section.

\section{Parametric study and results}

\subsection{Details of parametric numerical models}

Parametric studies were performed to investigate the structural response and failure pattern of axially restrained austenitic stainless steel beams in fire, with a focus on the influence of catenary action and restraint axial forces. The analyses were performed on conventionally welded IPE400 ( $H=400 \mathrm{~mm}, B=180 \mathrm{~mm}, t_{w}=8.6 \mathrm{~mm}$ and $t_{f}=13.5 \mathrm{~mm}$ ) beams with a length of $8 \mathrm{~m}$ loaded in the three-point bending configuration - the designation IPE refers to European standard universal I beams with parallel flanges. While different loading types e.g. uniformly or non-uniformly distributed loading in combination with point loads may be applied in real beams, the fundamental case of a beam with a point load at mid-span has been considered herein to obtain a comparative insight into the basic flexural response of axially restrained stainless steel and carbon steel beams exposed to elevated temperature. The selected cross-section is classified as Class 1 according to the cross-section classification limits set out in EN 1993-1-4 [21].

For a building subjected to a compartment fire, the action of cooler adjacent structures to the heated structural members can be represented by suitable end restrain conditions which may approximated by elastic end springs with representative axial and rotational stiffness. This approach was also adopted in the numerical modelling study performed herein with the effects of different restraint stiffness values considered in the parametric analysis [12, 22]. Axially restrained stainless steel beams with different levels of axial restraint stiffness ratios $\alpha_{A}$ equal to $0.02,0.05,0.15,0.3,0.5$ and 1 and with no axial restraint and full axial restraint were modelled under three different load levels equal to $30 \%, 50 \%$ and $70 \%$. The axial restraint stiffness ratio $\alpha_{A}$ is defined as the ratio of the axial restraint stiffness to the axial stiffness of the beam at room temperature $E A / L=202 \mathrm{kN} / \mathrm{mm}$, where $\mathrm{E}$ is the Young's modulus at room temperature, $\mathrm{A}$ is the cross-sectional area and $\mathrm{L}$ is the beam length. The range of the investigated axial restraint stiffness ratios were considered to contain all possible axial restraint levels that may be experienced by steel beams in practice as employed in similar investigations by Yin and Wang [12] and Najafi and Wang [22]. Load level is as defined in Section 3.1 - the ratio of the maximum bending moment to the plastic bending moment capacity at ambient temperature of the modelled beams. Beam end rotational restraints were not included due to the low rotational stiffness of connections in simple construction. Also, the fact that the beam response is mainly through axial tension in the catenary stage, the contribution of beam flexure and the possible benefits of rotational restraints diminishes to low levels [22]. The temperature distribution was assumed to be uniform across the depth of the modelled cross-sections. For comparison purposes, carbon steel beams with the same levels of axial restraint stiffness ratios as those adopted for the stainless steel beams and with $50 \%$ load level were also modelled. Table 2 presents a summary of the examined axially restrained beams.

The same modelling procedure as adopted in Section 3.2 were used with the input parameters for carbon steel models taken as those described previously and those for stainless steel models taken as those described hereafter. The two-stage Ramberg-Osgood model presented in Eqs. (1) and (2) as recommended in [23] was employed for modelling of the stainless steel beams. The room 
temperature material properties recommended by Afshan et al. [24] for hot-rolled austenitic stainless steel plates together with the elevated temperature strength and stiffness reduction factors pertaining to grade EN 1.4571 provided in Table 8.1 of the Design Manual for Structural Stainless Steel [23] were employed. In Eqs. (1) and (2), $\sigma_{\theta}$ and $\varepsilon_{\theta}$ are the engineering stress and strain at temperature $\theta$ respectively, $E_{\theta}$ is the Young's modulus at temperature $\theta, f_{y, \theta}$ is the yield stress at temperature $\theta$ (taken as the $0.2 \%$ proof stress), $E_{0.2, \theta}$ is the tangent modulus of the stress-strain curve at $f_{y, \theta}, \varepsilon_{y, \theta}$ is the total strain corresponding to $f_{y, \theta}, \varepsilon_{u, \theta}$ is the strain at ultimate tensile stress $f_{u, \theta}$ and $n_{\theta}$ and $m_{\theta}$ are the Ramberg-Osgood model parameters at temperature $\theta$.

$$
\begin{gathered}
\varepsilon_{\theta}=\frac{\sigma_{\theta}}{\mathrm{E}_{\theta}}+0.002\left(\frac{\sigma_{\theta}}{\mathrm{f}_{\mathrm{y}, \theta}}\right)^{\mathrm{n}_{\theta}} \text { for } \sigma_{\theta} \leq \mathrm{f}_{\mathrm{y}, \theta} \\
\varepsilon_{\theta}=\frac{\sigma_{\theta}-\mathrm{f}_{\mathrm{y}, \theta}}{\mathrm{E}_{0.2, \theta}}+\varepsilon_{\mathrm{u}, \theta}\left(\frac{\sigma_{\theta}-\mathrm{f}_{\mathrm{y}, \theta}}{\mathrm{f}_{\mathrm{u}, \theta}-\mathrm{f}_{\mathrm{y}, \theta}}\right)^{\mathrm{m}_{\theta}}+\varepsilon_{\mathrm{y}, \theta} \text { for } \mathrm{f}_{\mathrm{y}, \theta}<\sigma_{\theta} \leq \mathrm{f}_{\mathrm{u}, \theta}
\end{gathered}
$$

The standard ISO 834 temperature-time curve given in EN 1992-1-2 [9] was used for the thermal model. The convective heat transfer coefficient factor and the emissivity were taken as $25 \mathrm{~W} / \mathrm{m}^{2} \mathrm{~K}$ and 0.4, respectively, as specified in EN 1993-1-2 [9]. Thermal properties including specific heat, thermal expansion and thermal conductivity as recommended in [23] for austenitic stainless steels were employed. The global imperfection amplitude was set to $L / 1000$ for all stainless steel beams [17]. The local imperfection amplitudes were determined by means of the Dawson and Walker model, as adapted for stainless steel [18]. The residual stress patterns associated with conventionally welded stainless steel I-sections proposed by Yuan et al. [25] were incorporated into the FE models. The models were laterally restrained to avoid lateral-torsional buckling failure. Vertical stiffeners were also added below the loading point and between the loading point and the end supports to prevent local bearing failure of the web.

\subsection{Results and discussions}

\subsubsection{Deflection and axial force responses of stainless steel beams}

Figures 11 (a)-(c) compare the deflection-temperature curves from the parametric FE models of stainless steel beams with varying axial restraint stiffness ratios subjected to $30 \%, 50 \%$ and $70 \%$ load levels, respectively. For each of the considered load levels, there is little difference in the deflection-temperature behaviour of the modelled beams during Stage I response up to where the runaway deflections begin. The temperature at which the beam deflection starts to runaway is a function of the axial restraint stiffness, and, as expected, is lower for the beams with higher restraint stiffnesses. During Stage II, the deterioration of strength and stiffness of stainless steel with increasing temperatures dominates the structural response and causes further deflections, which are higher for higher applied load levels. Additional deflections arise due to the $P-\delta$ effects which are also higher for beams with higher axial restraint stiffness and under higher load levels. As a results, the onset of catenary action, which is triggered by the occurrence of large deflections, takes place at lower temperatures for beams under higher applied load levels. However, for a given load level, catenary action began almost at the same temperature for all different levels of axial restraint stiffness. 
The axial force-temperature curves from the parametric FE models of stainless steel beams with varying axial restraint stiffness ratios subjected to 30\%, 50\% and 70\% load levels are shown in Figures 12 (a)-(c), respectively. It can be observed that the axial compressive force generated as a result of the restrained thermal expansion strains grows steadily with increasing temperature for all beams until a maximum compressive axial force is reached, beyond which the axial force starts to reduce as the deflections start to runaway. The maximum axial compressive force reached is higher for beams with higher axial restraint stiffness, and results in earlier onset of runaway deflections for these beams. During the catenary stage, the axial force changes to tension and the applied vertical load on the beam is supported by the vertical component of the tensile catenary force. The magnitude of the axial tensile force developed during the catenary stage depends on the residual tensile strength of the material at elevated temperatures and the magnitude of the applied vertical load, which is shown in Figures 12 (a)-(c) to be larger for higher load levels and higher axial restrain stiffness levels.

\subsubsection{Comparison of stainless steel and carbon steel beam responses}

Figure 13 compare the deflection-temperature relationships of the axially restrained stainless steel and carbon steel beams with varying levels of axial restraint stiffness and under 50\% load level. Prior to the start of runaway deflections, stainless steel beams deflect slightly more than carbon steel beams for all levels of axial restraint stiffness. This is due to the higher axial compressive forces that develop as a result of the higher thermal expansion of stainless steel, which in turn give rise to higher $P$ - $\delta$ deflections. For low levels of axial restraint stiffness (up to 0.05 herein), the runaway deflections start at higher temperatures for stainless steel beams, as the superior strength and stiffness properties of stainless steel outperform the effects of higher restraint forces being developed. As a result, the start of catenary action also takes place at higher temperatures. In stainless steel beams with higher axial restraint stiffnesses ( 0.15 and beyond herein), while the higher axial compressive forces developed will cause early runaway deflections than for equivalent carbon steel beams, the onset of catenary action takes place at higher temperatures. The delay in reaching catenary action is due to the lower deflections at high temperatures that result from the superior stiffness retention of stainless steel over these higher temperatures.

Figure 14 compare the axial force-temperature responses of the stainless steel and carbon steel beams with different levels of axial restraint stiffness and subjected to $50 \%$ load level. For all axial restraint stiffnesses levels, the axial compressive force grows at a higher rate in stainless steel beams than carbon steel beams, demonstrating the higher thermal expansion of the material. For low levels for axial restraint stiffness (up to 0.05 herein), the stainless steel beams are however capable of reaching their peak axial compressive loads, prior to the onset of runaway deflections, at higher temperatures, while for higher levels of axial restraint stiffness stiffnesses $(0.15$ and beyond herein), the maximum axial compressive load is reached at increasingly lower temperatures with increasing levels of axial restraint stiffness. For all stainless steel beams, the catenary stage begins at higher temperatures $\left(750-850^{\circ} \mathrm{C}\right.$ range) than the carbon steel beams (550$650{ }^{\circ} \mathrm{C}$ range); this is due to the comparatively higher strength and stiffness retention factor possessed by the stainless steel at high temperatures. The maximum tensile catenary force reached for both stainless steel and carbon steel beams are however very similar; this is due to the comparable residual ultimate tensile force possessed by the beams at their respective catenary stage temperature ranges. 


\section{Simplified analytical model}

Fire engineering design approaches for restrained steel beams in fire have been developed by a number of researchers [13-14, 20]. The aim of these studies was to establish simple design methodologies for evaluating the thermally induced forces and deflections in restrained beams when exposed to fire to allow an assessment of the strength and stability of the frame system and in particular the connections. In this section, an approximate analytical solution for the axial forcetemperature responses of axially restrained stainless steel beams in fire is developed and verified against the parametric study results presented in Section 4.

\subsection{Development of model}

Figure 15 illustrates the simplified model of the axial force-temperature response of an axially restrained beam at elevated temperatures, with the key behavioural stages described in the followings. The beam within the OA stage acts as a flexural member with axial compressive force due to the presence of the axial restraints. The compressive axial force increases linearly with temperature until buckling of the member under the combined action of compression and bending moment occurs at point $\mathrm{A}$. This is followed by a linear decrease in the compressive force from point $\mathrm{A}$ to point $\mathrm{B}$, referred to as the transition temperature point. In the next stage, $\mathrm{BC}$, the beam enters the catenary phase and acts in combined flexure and tensile axial force, where point $\mathrm{C}$ marks the maximum tensile axial force (catenary force) reached, beyond which, the decreasing variation of the tensile axial force follows the plastic tensile capacity of the beam i.e. the degradation of the steel yield strength with increasing temperature. The derivation of the proposed axial force-temperature relationship for an axially restrained beam as shown in Figure 16 is described hereafter.

Response region $O A$ - maximum compressive force

For the beam model shown in Figure 16 with the axial end restraints represented by a spring with stiffness $k_{A}$ and subjected to a uniform temperature distribution $\Delta \theta$ across the cross-section, the free thermal strain $\varepsilon_{t h}$ and the mechanical strain $\varepsilon_{m e c}$ of the member may be determined from Eqs (3) and (4), respectively, where $\alpha$ is the coefficient of thermal expansion, $N_{c, \theta}$ is the axial compressive force at temperature $\theta$ and $E_{\theta}$ and $A$ are the Young's modulus at temperature $\theta$ and cross-sectional area of the beam, respectively. The total axial strain $\Delta L / L=N_{c, \theta} / k_{A} L$, where, $\Delta L$ is the total change in length and $L$ is the initial length of the beam, is related to the thermal and mechanical strains as given by Eq. (5), which may in turn be used to obtain an explicit equation for the axial compressive force $N_{c, \theta}$, as presented in Eq. (6). The axial force $N_{c, \theta}$ in region OA may be obtained by solving Eq. (6) for incremental temperatures $\Delta \theta$. The maximum compressive axial force $N_{c, \max }$ and its corresponding temperature $\theta_{N, c, \max }$, i.e. point A on Figure 16, is determined by applying the combined bending and axial compression interaction relationship limit set out in Clause 4.2.3.5 of Eurocode 3 - Part 1.2 [9] as described by Eq. (7), where $M_{0}$ is the maximum applied bending moment, $N_{b, R d, \theta}$ and $M_{c, R d, \theta}$ are the member flexural buckling resistance and the cross-section bending moment resistance at temperature $\theta$, respectively and $k_{y}$ is the combined loading interaction factor. The design resistance parameters $N_{b, R d, \theta}, M_{c, R d, \theta}$ and $k_{y}$ should be taken from Eurocode 3 - Part 1.2 [9].

$$
\varepsilon_{\mathrm{th}}=\alpha(\Delta \theta)
$$




$$
\begin{gathered}
\varepsilon_{\mathrm{mec}}=\mathrm{N}_{\mathrm{c}, \theta} / \mathrm{E}_{\theta} \mathrm{A} \\
\alpha(\Delta \theta)-\mathrm{N}_{\mathrm{c}, \theta} / \mathrm{E}_{\theta} \mathrm{A}=\Delta \mathrm{L} / \mathrm{L}=\mathrm{N}_{\mathrm{c}, \theta} / \mathrm{k}_{\mathrm{A}} \mathrm{L} \\
\mathrm{N}_{\mathrm{c}, \theta}=\left[\alpha(\Delta \theta) \mathrm{E}_{\theta} \mathrm{A}\right] /\left[1+\mathrm{E}_{\theta} \mathrm{A} / \mathrm{k}_{\mathrm{A}} \mathrm{L}\right] \\
\mathrm{N}_{\mathrm{c}, \theta} / \mathrm{N}_{\mathrm{b}, \mathrm{Rd}, \theta}+\mathrm{k}_{\mathrm{y}} \mathrm{M}_{0} / \mathrm{M}_{\mathrm{c}, \mathrm{Rd}, \theta} \leq 1.0
\end{gathered}
$$

\section{Response region $A B$ - transition temperature}

At the transition temperature $\theta_{T}$ i.e. the temperature at which the beam enters the catenary action phase, the axial force $N_{c, \theta}$ is zero and from Eq. (7), the maximum applied bending moment $M_{0}=$ $M_{c, R d, \theta}=W_{p l, y} f_{y} k_{y, \theta}$, where $W_{p l, y}$ is the plastic section modulus, $f_{y}$ is the yield strength at room temperature and $k_{y, \theta}$ is the yield strength reduction factor at temperature $\theta$. Hence, an estimate for the transition temperature $\theta_{T}$, point $\mathrm{B}$ on Figure 16, may be obtained as the temperature at which $M_{0}=M_{c, R d, \theta}$ i.e. the failure temperature of the unrestrained beam.

\section{Response region $B C$ - maximum tensile force}

When the maximum tensile force $N_{t, \max }$ in the catenary response range is reached, the applied bending moment $M_{0}$ is resisted by catenary action only, as described by the equilibrium equation presented in Eq. (8), where $\delta_{v, \max }$ is the maximum mid-span deflection of the beam, $A$ is the crosssectional area and all other symbols are as previously defined. The deflection profile shown in Figure 17 and described by Eq. (9), proposed by Dwaikat and Kodour [14] and used by Iqbal et al. [26], was adopted herein to provide an estimate for the maximum mid-span deflection $\delta_{v \text {, max }}$ of the beam in the catenary response range. Eq. (8) together with Eq. (9) may be evaluated for incremental temperatures $\Delta \theta$ for $\theta>\theta_{T}$, to determine the maximum tensile force $N_{t, \max }$ and its corresponding temperature $\theta_{N, t, \max }$.

The FE parametric results from Section 4 show that the maximum tensile catenary force reached increases with increasing levels of axial restraint stiffness $\alpha_{A}$. Hence, to include this effect, $N_{t, \max }$ obtained from Eq. (8) is multiplied by an axial restraint factor $F_{\alpha, A}$ as given in Eq. (10) to obtain point $\mathrm{C}$ on Figure 15 with $N_{t, \max }^{*}$ at $\theta_{N, t, \max }^{*}=\theta_{N, t, \max }$. The axial restraint factor $F_{\alpha, A}$ employed is given by Eq. (11). This was derived on the basis of the parametric FE results, where a power law model was fitted to the normalised maximum tensile force $N_{t, \text { max,partial }} / N_{t, \text { max }}$ full (averaged for different load levels) versus the axial restraint stiffness $\alpha_{A}$ results as shown in Figure 18, where $N_{t, \text { max,partial }}$ and $N_{t, \text { max full }}$ are the maximum tensile force for beams with partial and full axial restraints, respectively. A similar approach was employed by Najafi and Wang [27] in their study of perforated steel beams in fire.

$$
\begin{gathered}
\mathrm{M}_{0}=\mathrm{N}_{\mathrm{t}, \text { max }} \delta_{\mathrm{v}, \text { max }}=\mathrm{Af}_{\mathrm{y}} \mathrm{k}_{\mathrm{y}, \theta} \delta_{\mathrm{v}, \text { max }} \\
\delta_{\mathrm{v}, \text { max }}=\sqrt{\left(\left(\mathrm{L}_{0}+\Delta \mathrm{L}\right) / 2\right)^{2}+\left(\mathrm{L}_{0} / 2\right)^{2}} \text { with } \Delta \mathrm{L}=\alpha(\Delta \theta) \mathrm{L}_{0} \\
\mathrm{~N}_{\mathrm{t}, \text { max }}^{*}=\mathrm{F}_{\alpha \mathrm{A}} \mathrm{N}_{\mathrm{t}, \text { max }}
\end{gathered}
$$




$$
\mathrm{F}_{\alpha \mathrm{A}}=1.023 \alpha_{\mathrm{A}}^{0.054} \text { but } \leq 1.0
$$

\subsection{Verification of model}

The results of the parametric modelling investigation were used to verify the predicted axial loadtemperature response from the simplified analytical model. Figures 19-21 compare the FE and the simplified analytical model axial load-temperature response profiles for the beams with $30 \%, 50 \%$ and $70 \%$ load levels, respectively, where it is shown that the proposed model is capable of predicting the overall response characteristics accurately. The key response parameters including the maximum compressive axial force $N_{c, \max }$ and its corresponding temperature $\theta_{N, c, \max }$, the transition temperature $\theta_{T}$ and the maximum tensile axial force $N_{t, \max }^{*}$ and its corresponding temperature $\theta_{N, t, \max }{ }$ from both the parametric FE models and the simplified analytical model are presented in Table 3. The mean and coefficient of variation (COV) for the FE/Model values of $N_{c, \text { max }}, \theta_{N, c, \max }, \theta_{T}, N^{*}{ }_{t, \max }$ and $\theta^{*}{ }_{N, t, \max }$ are also reported in Table 3 , which show the high degree of predictive accuracy of the model for all parameters.

\section{Conclusions}

The large deflection behaviour of axially restrained stainless steel I-sections beams in fire has been examined through a numerical investigation. FE models, validated rigorously against the results of physical tests, were used to conduct a parametric study on stainless steel beams with varying degrees of axial restraint stiffness and applied load levels subjected to elevated temperature. The results showed that the axially restrained stainless steel beams exhibit similar stages of behaviour in fire as has been observed for carbon steel beams. However, owing to the more favourable strength and stiffness retention factor of stainless steel at high temperatures, stainless steel beams are capable of withstanding comparatively higher temperatures before the onset of catenary action, while developing similar levels of maximum catenary force to carbon steel beams, despite the higher thermal expansion of the material. The results of the parametric study formed the basis for the verification of a simplified analytical model developed to predict the axial-load temperature response profile of axially restrained stainless steel beams at elevated temperatures. Comparisons between the results of FE and the analytical model were shown to be in excellent agreement, offering a simple approach for considering the effect of axial restraints in fire design of stainless steel structural frame systems.

\section{Acknowledgements}

This research was supported by the Institution of Civil Engineers (ICE) through the ICE Research and Development Enabling Fund which is gratefully acknowledged.

\section{References}

1. J. Chen, B. Young. Stress-strain curves for stainless steel at elevated temperatures. Engineering Structures. 2006; 28(2): 229-239.

2. L. Gardner, A. Insausti, K.T. Ng, M. Ashraf. Elevated temperature material properties of stainless steel alloys. Journal of Constructional Steel Research. 2010; 66(5): 634-647. 
3. Y. Huang, B. Young. Stress-strain relationship of cold-formed lean duplex stainless steel at elevated temperatures. Journal of Constructional Steel Research. 2017; 92: 103-113.

4. N. Baddoo, B.A. Burgan. Fire resistant design of austenitic structural stainless steel. Journal of Constructional Steel Research. 1998; 46(1): 458-459.

5. B. Uppfeldt, T. Ala Qutinen, M. Veljkovic. A design model for stainless steel box columns in fire. Journal of Constructional Steel Research. 2008; 64: 1294-1301.

6. N. Lopes, P. Vila Real, L. Simoes da Silva, J.M. Franssen. Numerical analysis of stainless steel beam-column in case of fire. Fire Safety Journal. 2012; 50: 35-50.

7. N. Tondini, B. Rossi, J.M. Franssen. Experimental investigation on ferritic stainless steel columns in fire. Fire Safety Journal. 2013, 62: 238-248.

8. Y. Huang, B. Young. Structural performance of cold-formed lean duplex stainless steel beams at elevated temperatures. Thin-Walled Structures. 2018; 129: 20-27.

9. EN 1993-1-2, Eurocode 3: Design of Steel Structures - Part 1.2: General Rules - Structural Fire Design, European Committee for Standardization (CEN), Brussels, 2005.

10. M. Gillie, A.S. Usmani, J.M. Rotter. A structural analysis of the first Cardington test. Journal of Constructional Steel Research. 2001; 57(6): 581-601.

11. T.C.H. Liu, M.K. Fahad, J.M. Davis. Experimental investigation of behaviour of axially restrained steel beams in fire. Journal of Constructional Steel Research. 2002; 58: 1211-1230.

12. Y.Z. Yin, Y.C. Wang. A numerical study of large deflection behaviour of restrained steel beams at elevated temperatures. Journal of Constructional Steel Research. 2004; 60(7): 10291047.

13. Y.Z. Yin, Y.C. Wang. Analysis of catenary action in steel beams using a simplified hand calculation method, Part 1: theory and validation for uniform temperature distribution. Journal of Constructional Steel Research. 2005; 61(2): 183-211.

14. M.M.S. Dwaikat, V.K.R Kodur. A performance based methodology for fire design of restrained steel beams. Journal of Constructional Steel Research. 2011; 67(3): 510-524.

15. ABAQUS, version 2016. Dassault Systèmes Simulia Corp. 2015.

16. A. Pournaghshband, S. Afshan, A.S.J. Foster. Structural fire performance of axially and rotationally restrained stainless steel columns. Thin-Walled Structures. 137: 561-572.

17. EN 1090-2, Execution of steel structures and aluminium structures - Part 2: Technical requirements for steel structures. European Committee for Standardization (CEN), Brussels, 2018.

18. R.G. Dawson, A.C. Walker. Post-buckling of geometrically imperfect plates. Journal of the Structural Division (ASCE). 1972; 98(1): 75-94.

19. Ultimate limit state calculation of sway frames with rigid joints. Technical Committee 8 (TC8) of European Convention for Constructional Steelwork (ECCS), Tech. Rep. No. 33.

20. T.C.H. Liu, J.M. Davies. Performance of steel beams at elevated temperatures under the effect of axial restraints. Steel and Composite Structures. 2001; 1(4): 427-440.

21. EN 1993-1-4, Eurocode 3: Design of Steel Structures - Part 1.4: General Rules Supplementary Rules for Stainless Steels, European Committee for Standardization (CEN), Brussels, 2015. 
22. M. Najafi, Y.C. Wang. Axially restrained steel beams with web openings at elevated temperatures, part 1: Behaviour and numerical simulation results. Journal of Constructional Steel Research. 2017; 128: 745-761.

23. Design Manual for Structural Stainless Steel, Forth Edition, Steel Construction Institute. 2017.

24. S. Afshan, O. Zhao, L. Gardner. Standardised material properties for numerical parametric studies of stainless steel structures and buckling curves for tubular columns. Journal of Constructional Steel Research. 2018; 152: 2-11.

25. H.X. Yuan, Y.Q. Wang, Y.J. Shi, L. Gardner. Residual stress distributions in welded stainless steel sections. Thin-Walled Structures. 2014; 79: 38-51.

26. N. Iqbal, T. Heistermann, M. Veljkovic, F. Lopes, A. Santiago, L.S. da Silva. Axial force and deformation of a restrained steel beam in fire - Description and validation of a simplified analytical procedure. Advanced Steel Construction. 2016; 12 (2):174-193.

27. M. Najafi, Y.C. Wang. Axially restrained steel beams with web openings at elevated temperatures, part 2: Development of an analytical method. Journal of Constructional Steel Research. 2017; 128:687-705. 


\section{Figures}

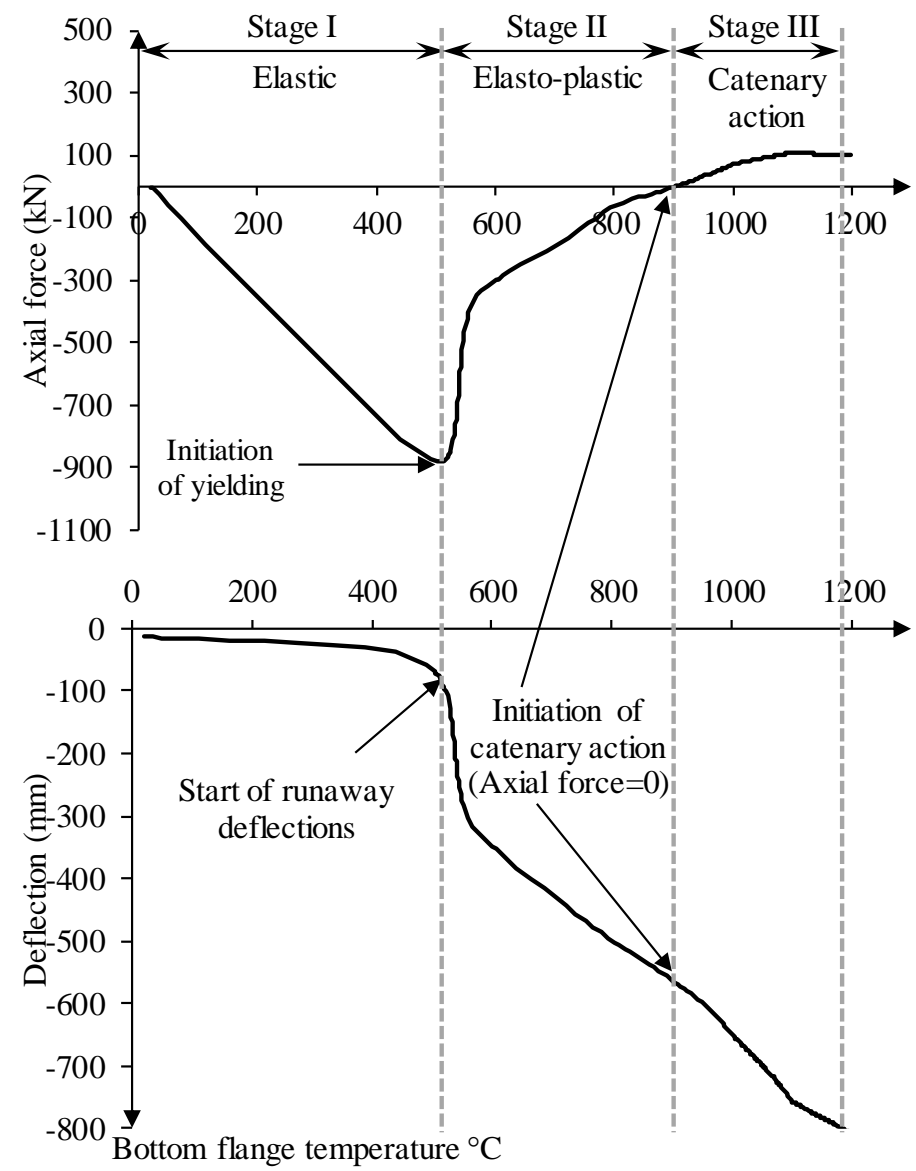

Fig. 1. The stages of behaviour of an axially and rotationally restrained beam in fire.

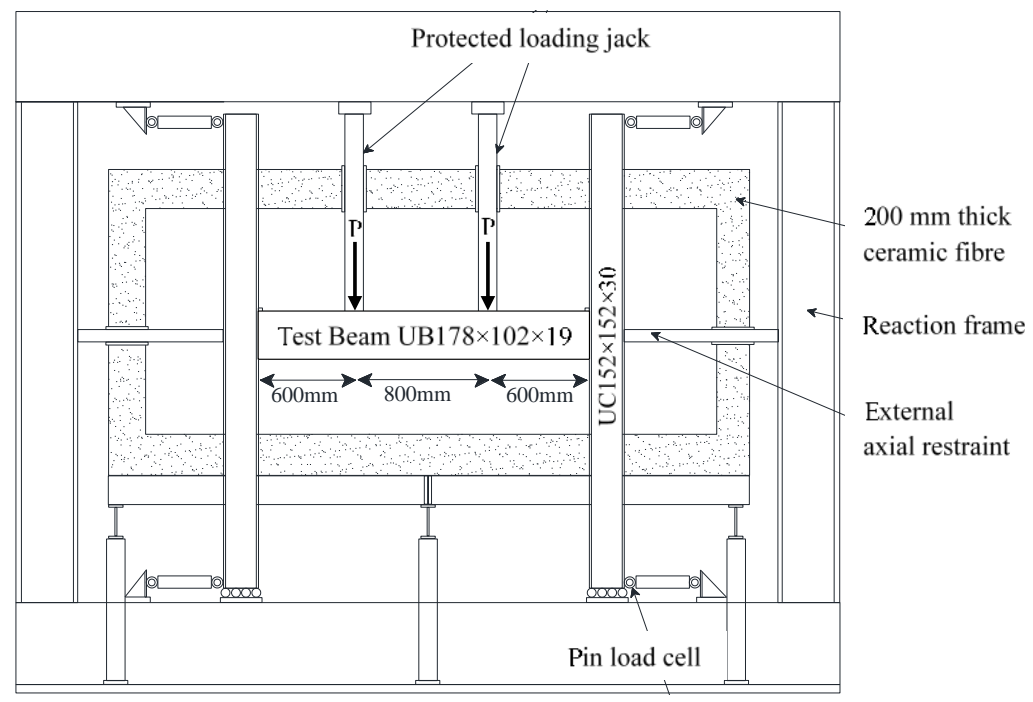

Fig. 2. Elevation view of the testing assembly employed by Liu et al. [11] and used for validation of FE models. 


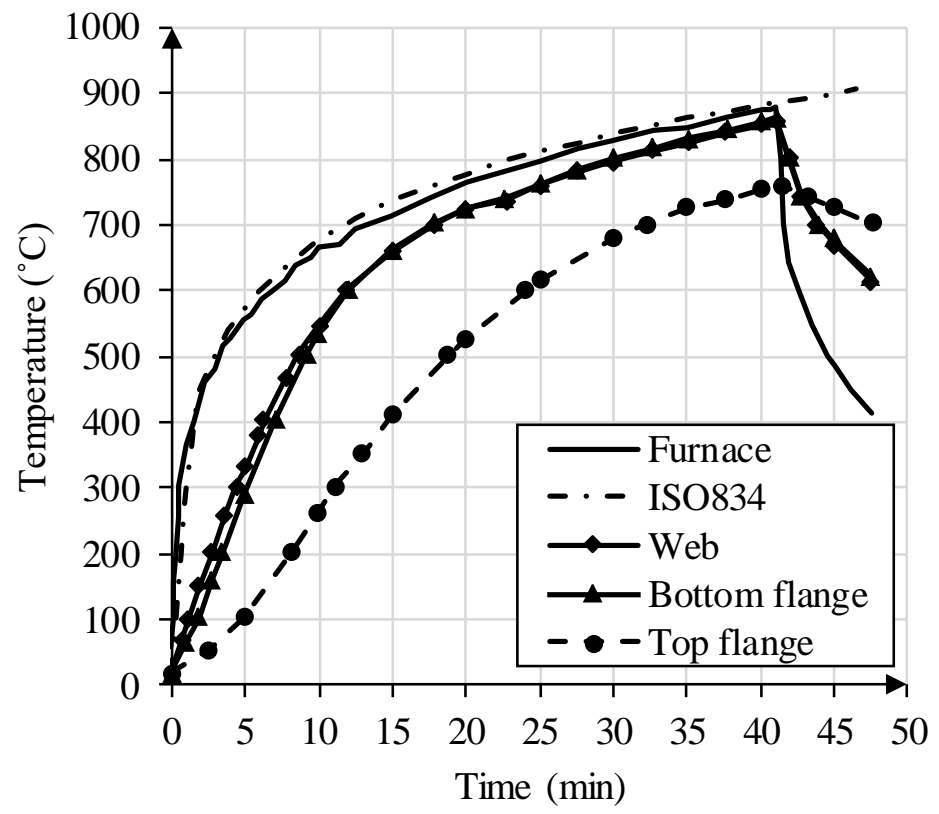

Fig. 3. Typical measured furnace and specimen temperature distributions reported in [11] and used for validation of FE models.

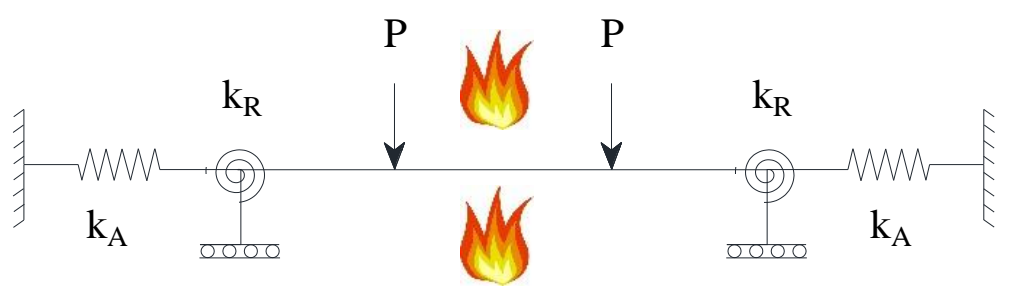

Fig. 4. Structural model of axially and rotationally restrained heated beam.

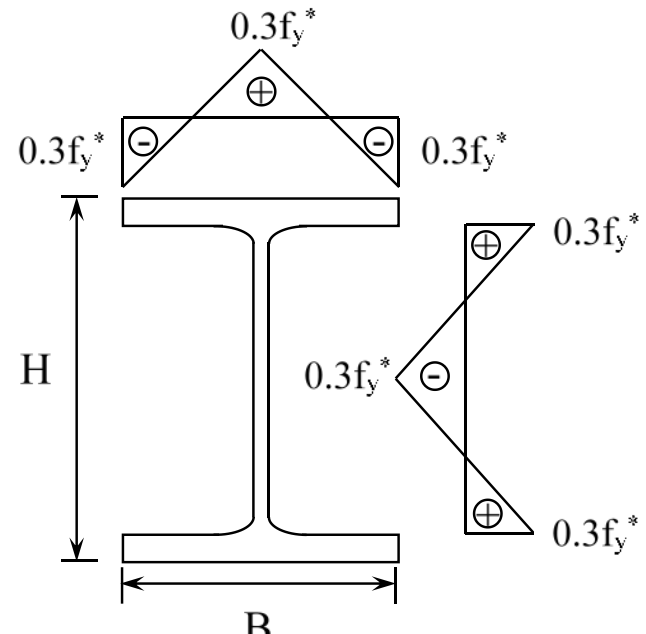

Fig. 5. Residual stress pattern applied to the carbon steel I-section beam. 


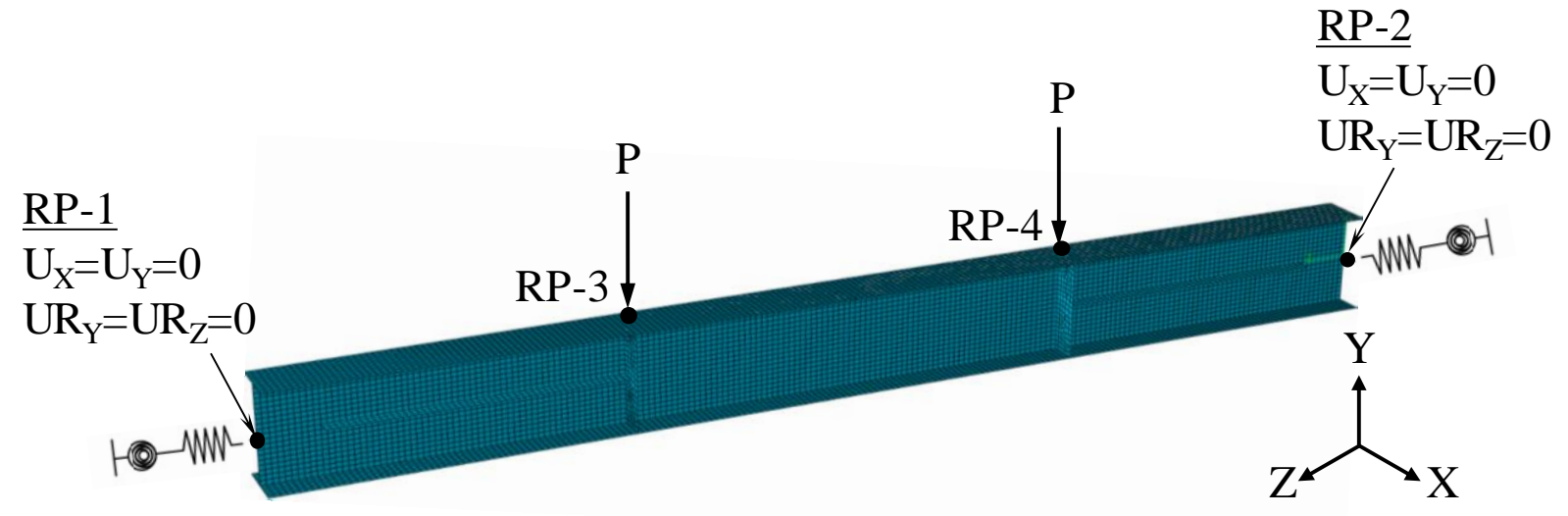

Fig. 6. Definition of boundary conditions for the stress analysis model.

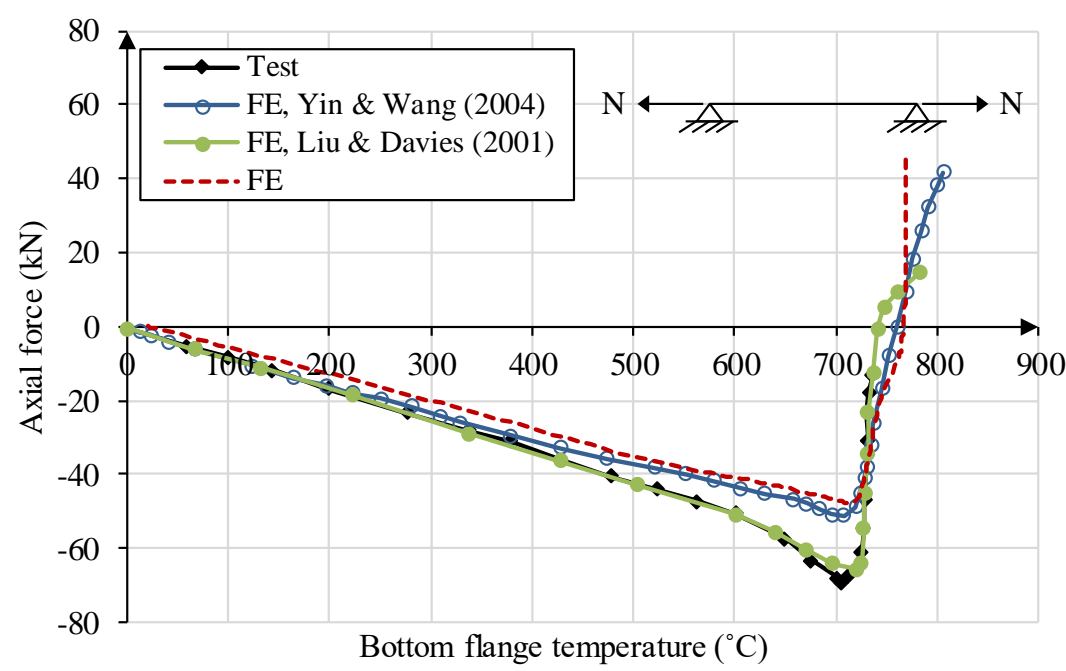

(a) Axial force-temperature

Bottom flange temperature $\left({ }^{\circ} \mathrm{C}\right)$

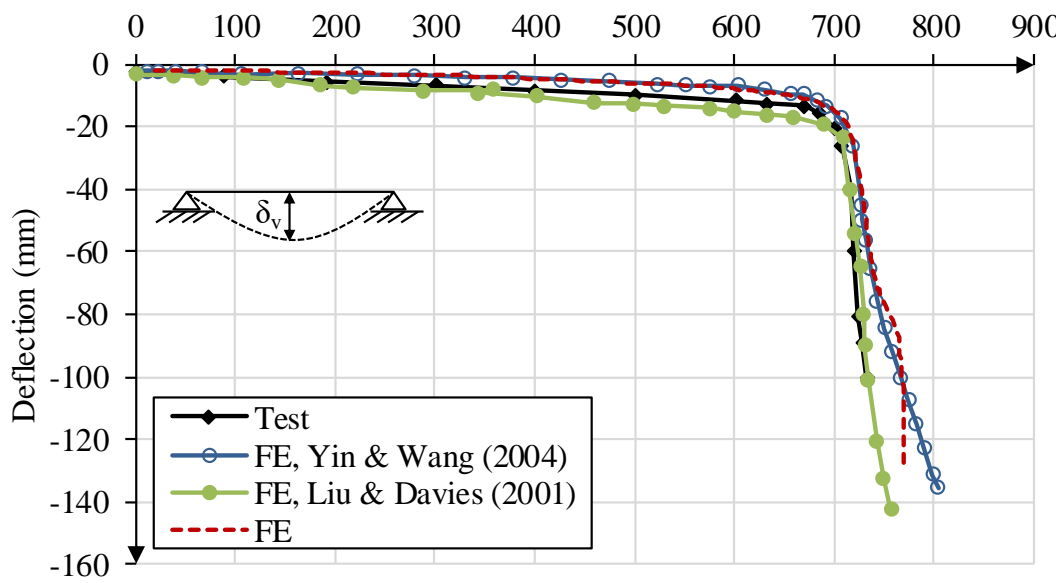

(b) Deflection-temperature

Fig. 7. Comparison of (a) axial force-temperature and (b) deflection-temperature responses from test and FE for FUR13 specimen - Flush end-plate connection, $\mathrm{k}_{\mathrm{A}}=8 \mathrm{kN} / \mathrm{mm}$ and load ratio $=0.5$. 


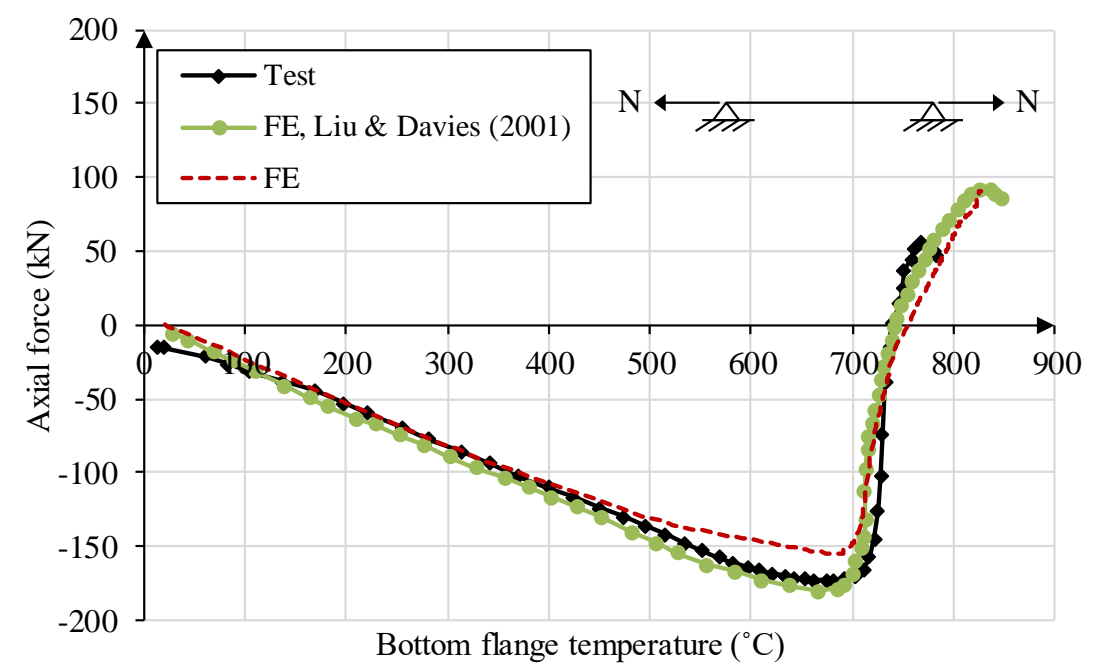

(a) Axial force-temperature

Bottom flange temperature $\left({ }^{\circ} \mathrm{C}\right)$

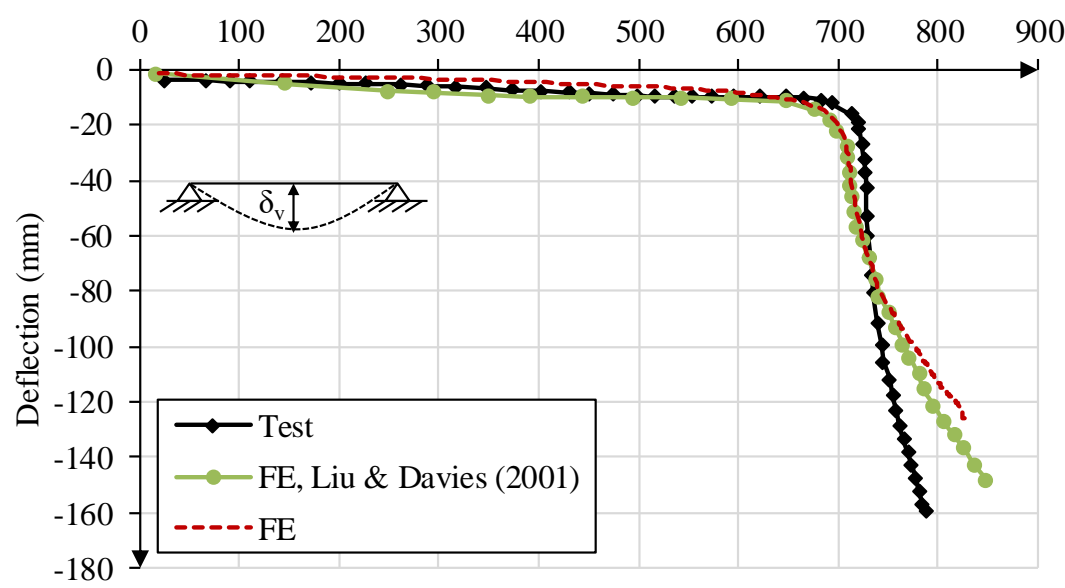

(b) Deflection-temperature

Fig. 8. Comparison of (a) axial force-temperature and (b) deflection-temperature responses from test and FE for FUR25 specimen - Flush end-plate connection, $\mathrm{k}_{\mathrm{A}}=35 \mathrm{kN} / \mathrm{mm}$ and load ratio $=0.5$. 


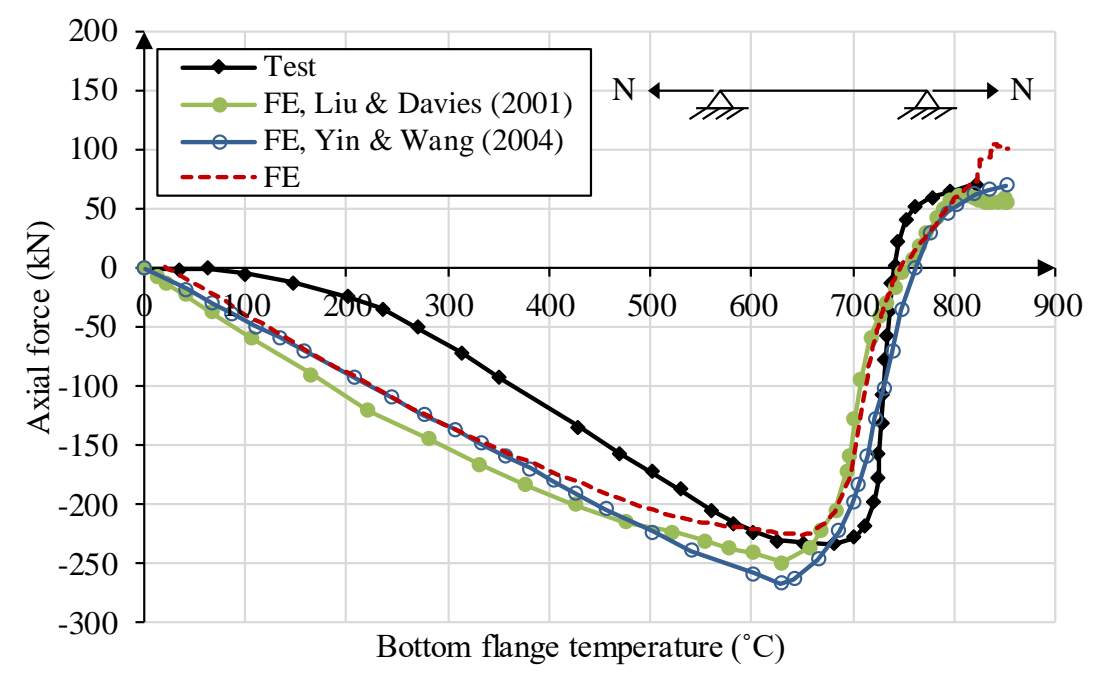

(a) Axial force-temperature

Bottom flange temperature $\left({ }^{\circ} \mathrm{C}\right)$

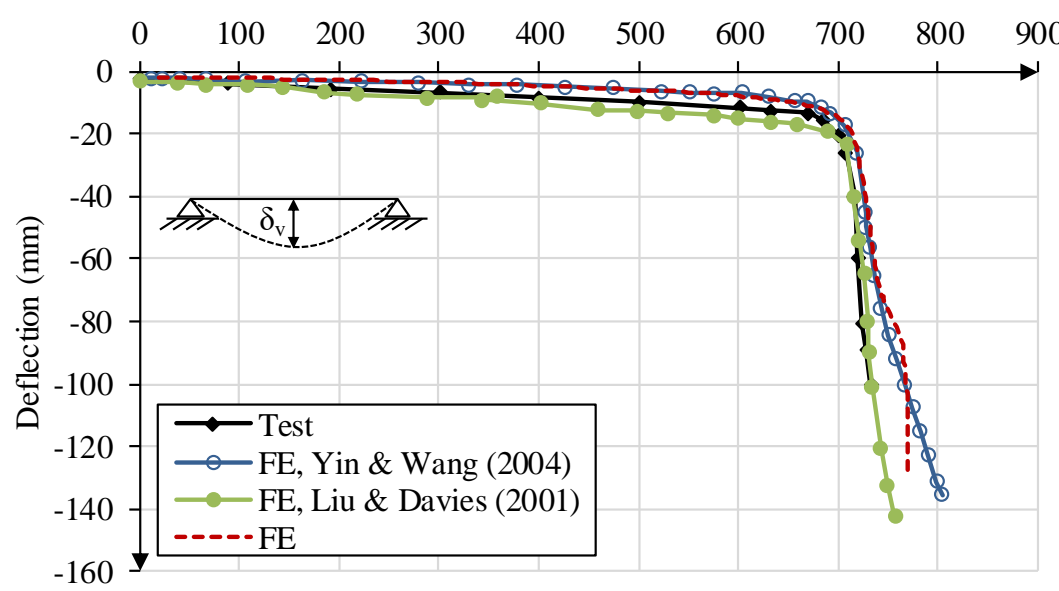

(b) Deflection-temperature

Fig. 9. Comparison of (a) axial force-temperature and (b) deflection-temperature responses from test and FE for FUR31 specimen - Flush end-plate connection, $\mathrm{k}_{\mathrm{A}}=62 \mathrm{kN} / \mathrm{mm}$ and load ratio $=0.5$.

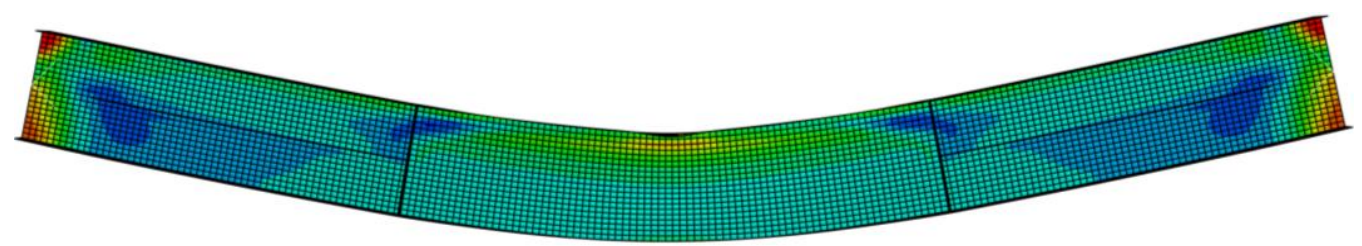

(a) Failure mode from FE.

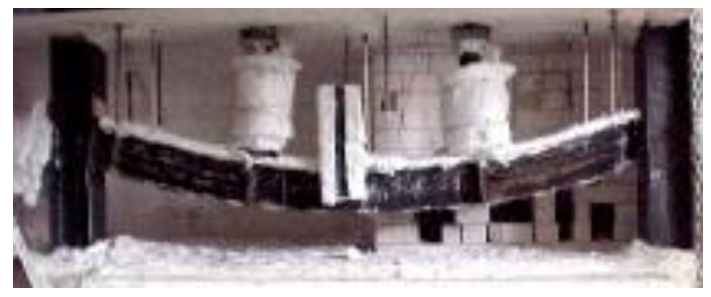

(b) Failure mode from experiments.

Fig. 10. Replication of experimentally [11] observed failure mode by numerical models. 


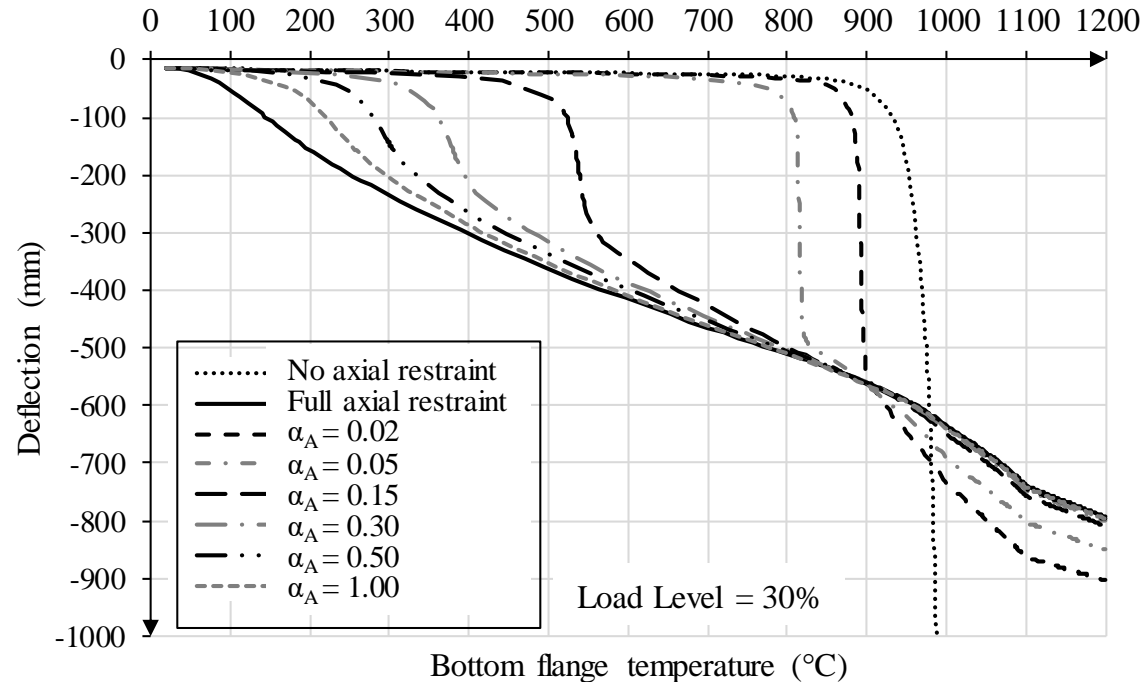

(a) Deflection-temperature response for $30 \%$ load level.

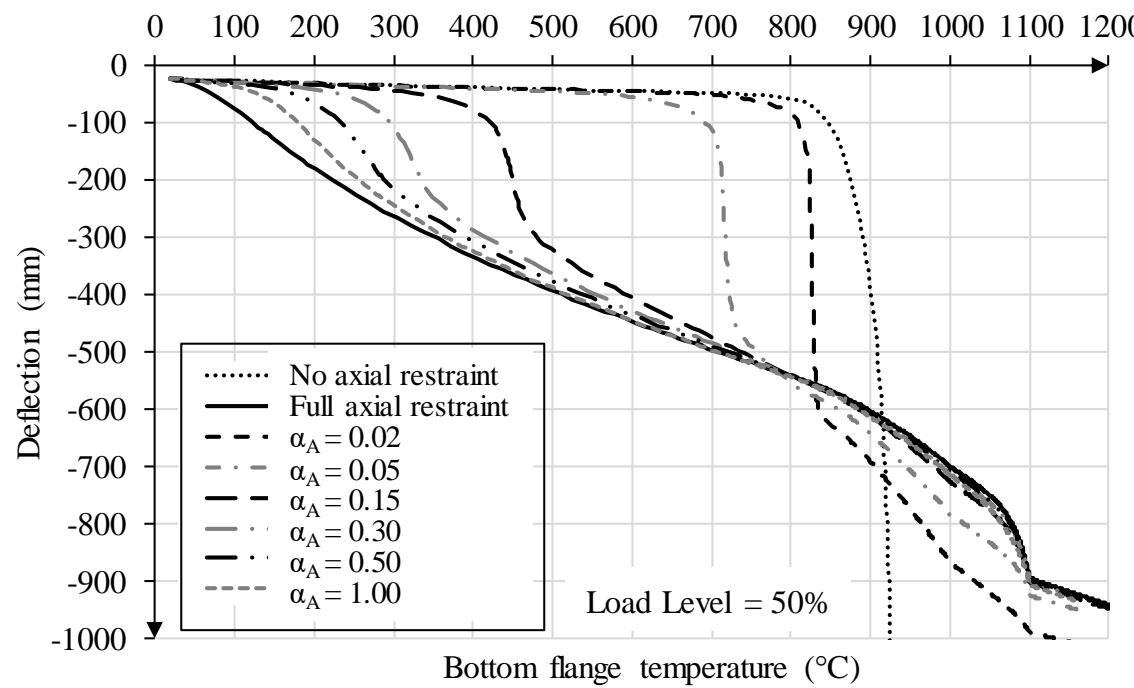

(b) Deflection-temperature response for $50 \%$ load level.

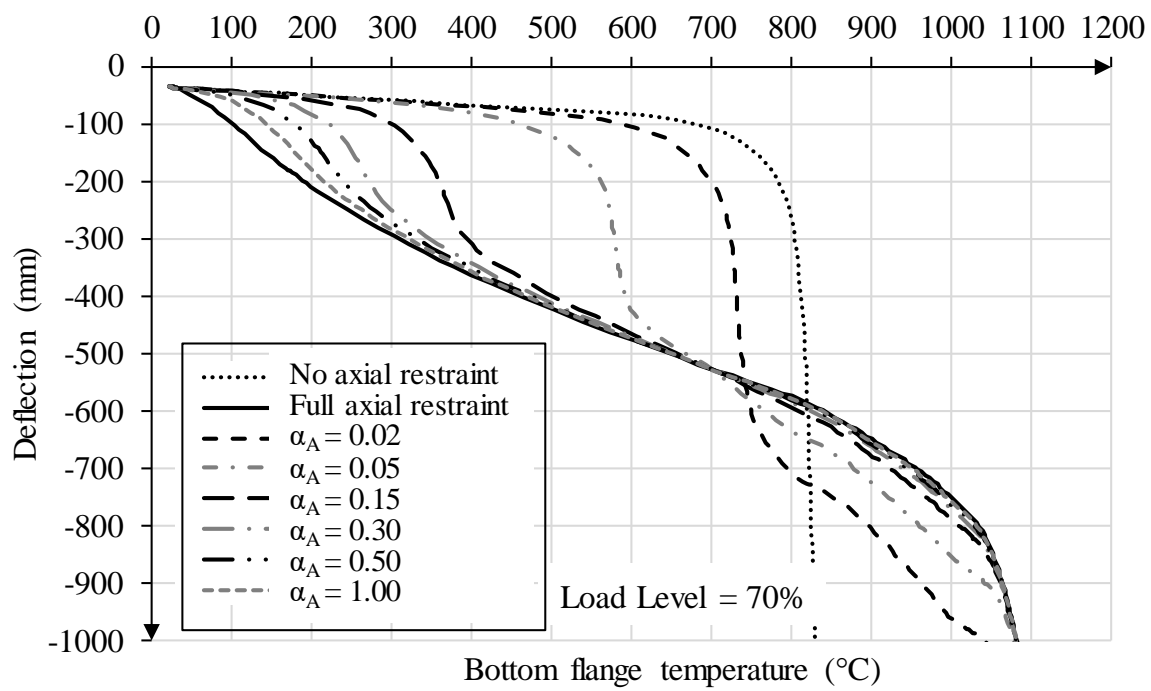

(c) Deflection-temperature response for $70 \%$ load level.

Fig. 11. Parametric axial deflection-temperature results for axially restrained stainless steel beams under (a) 30\%, (b) 50\% and (c) $70 \%$ load levels. 


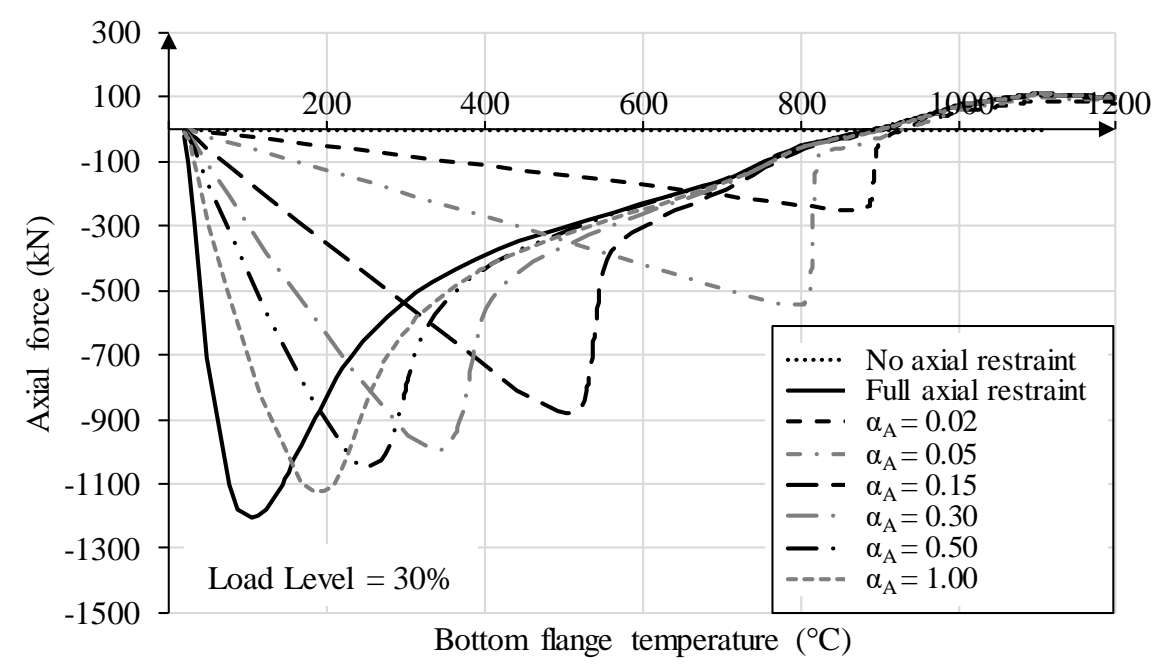

(a) Axial force-temperature response for $30 \%$ load level.

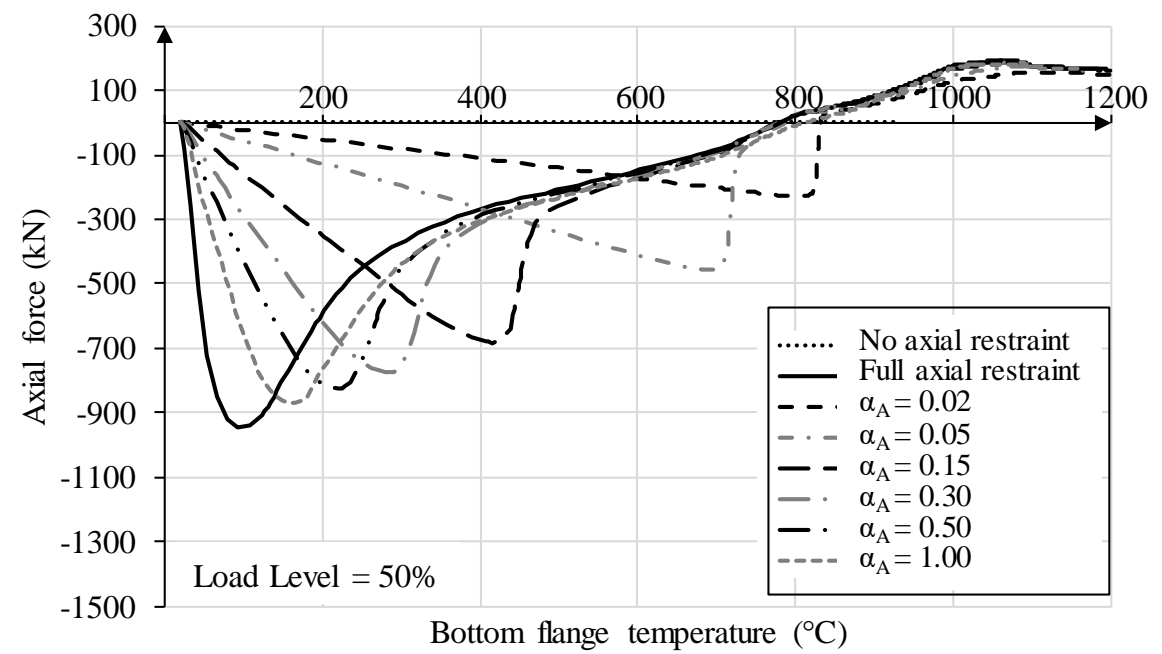

(b) Axial force-temperature response for $50 \%$ load level.

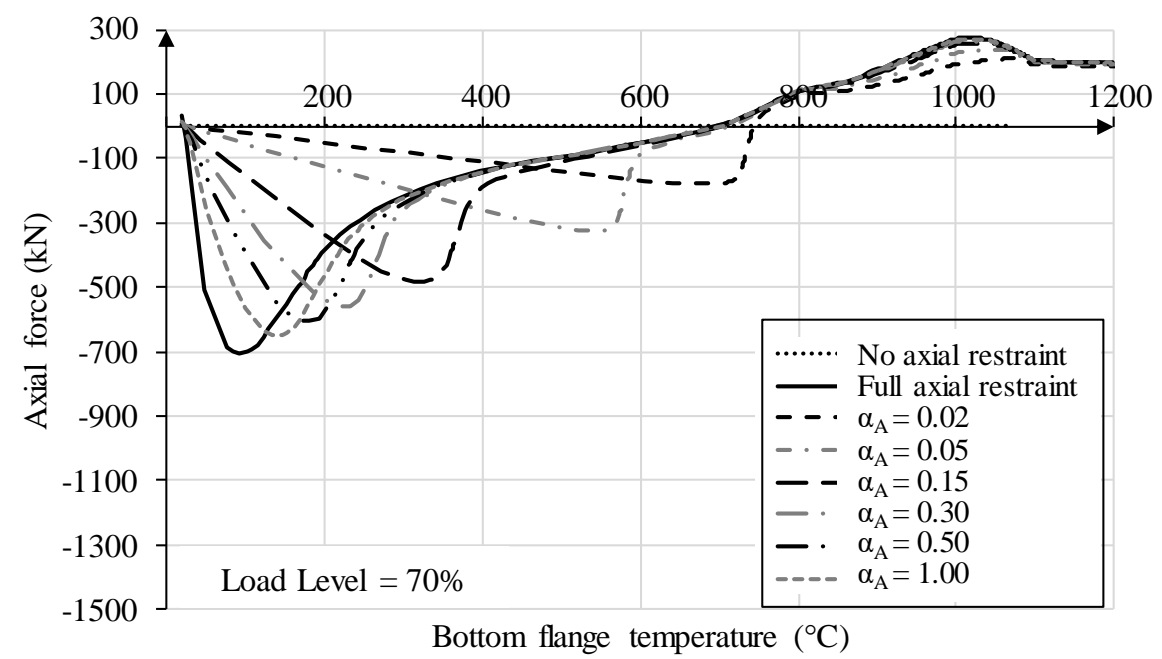

(c) Axial force-temperature response for $70 \%$ load level.

Fig. 12. Parametric axial force-temperature results for axially restrained stainless steel beams under (a) 30\%, (b) 50\% and (c) $70 \%$ load levels. 


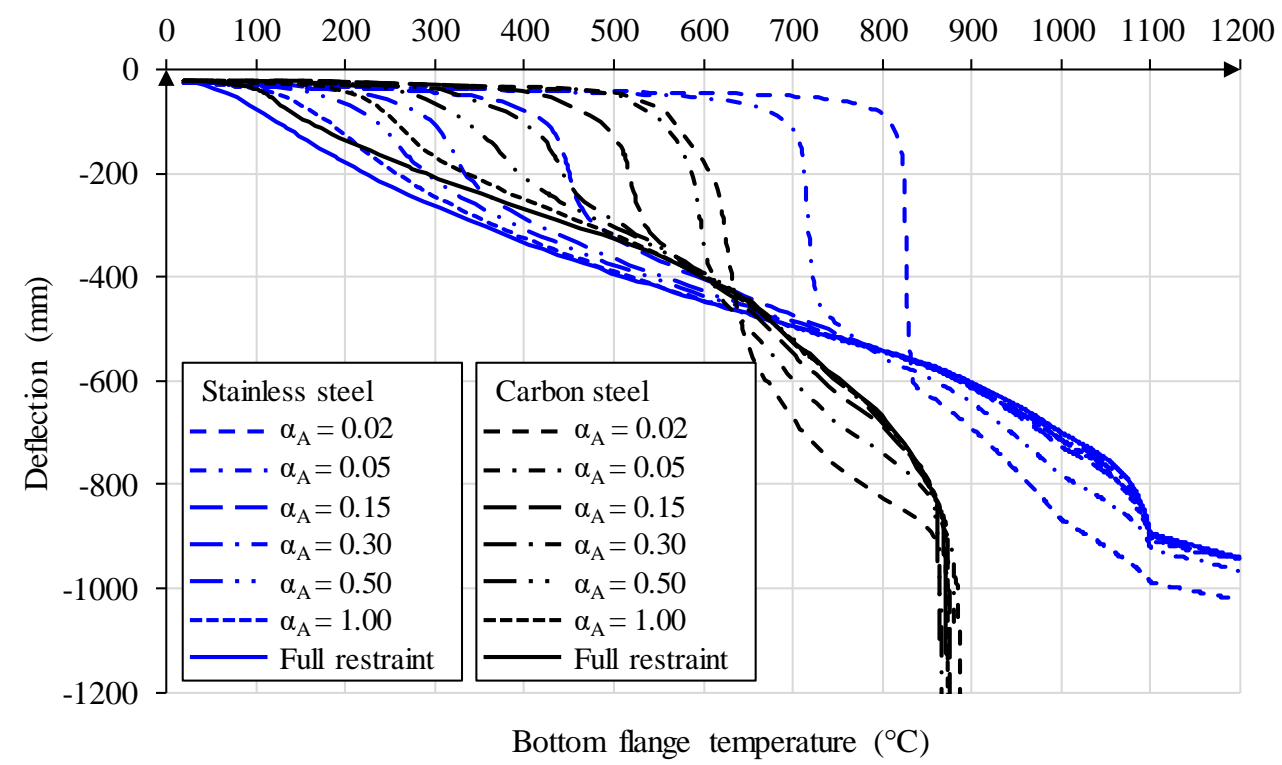

Fig. 13. Comparison of deflection-temperature responses of axially restrained stainless steel and carbon steel beams under 50\% load level.

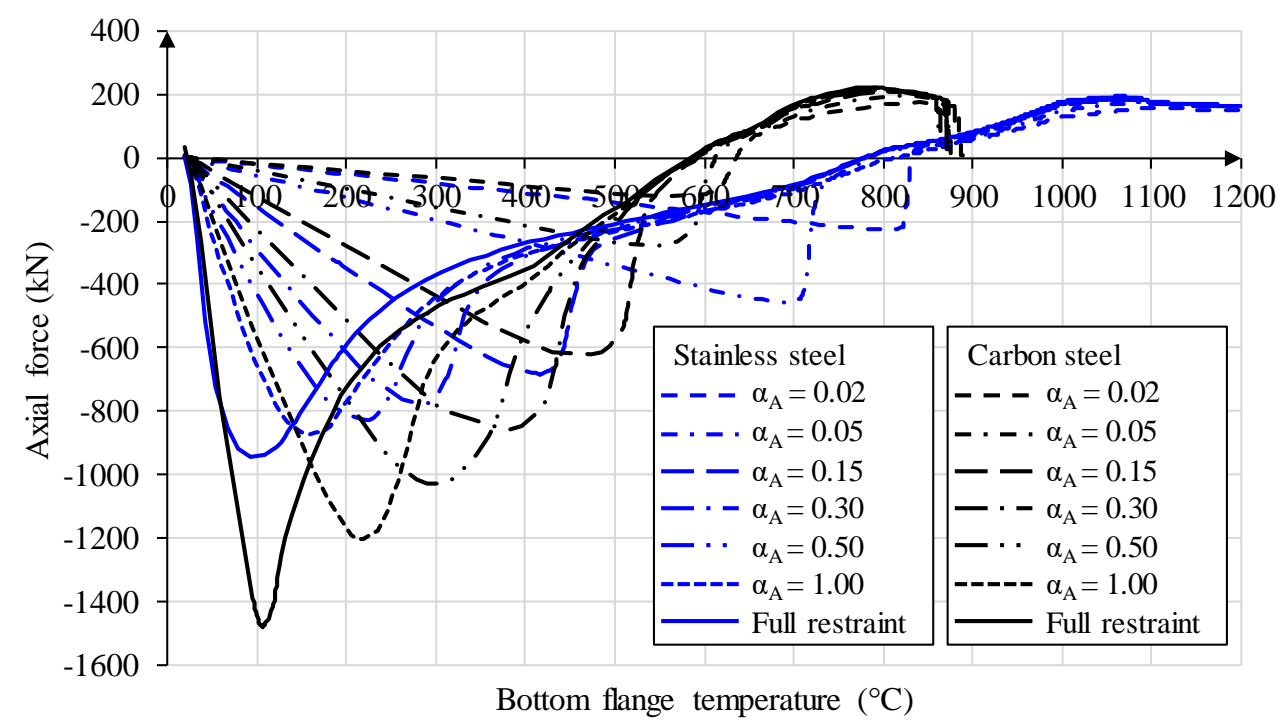

Fig. 14. Comparison of axial force-temperature responses of axially restrained stainless steel and carbon steel beams under 50\% load level. 


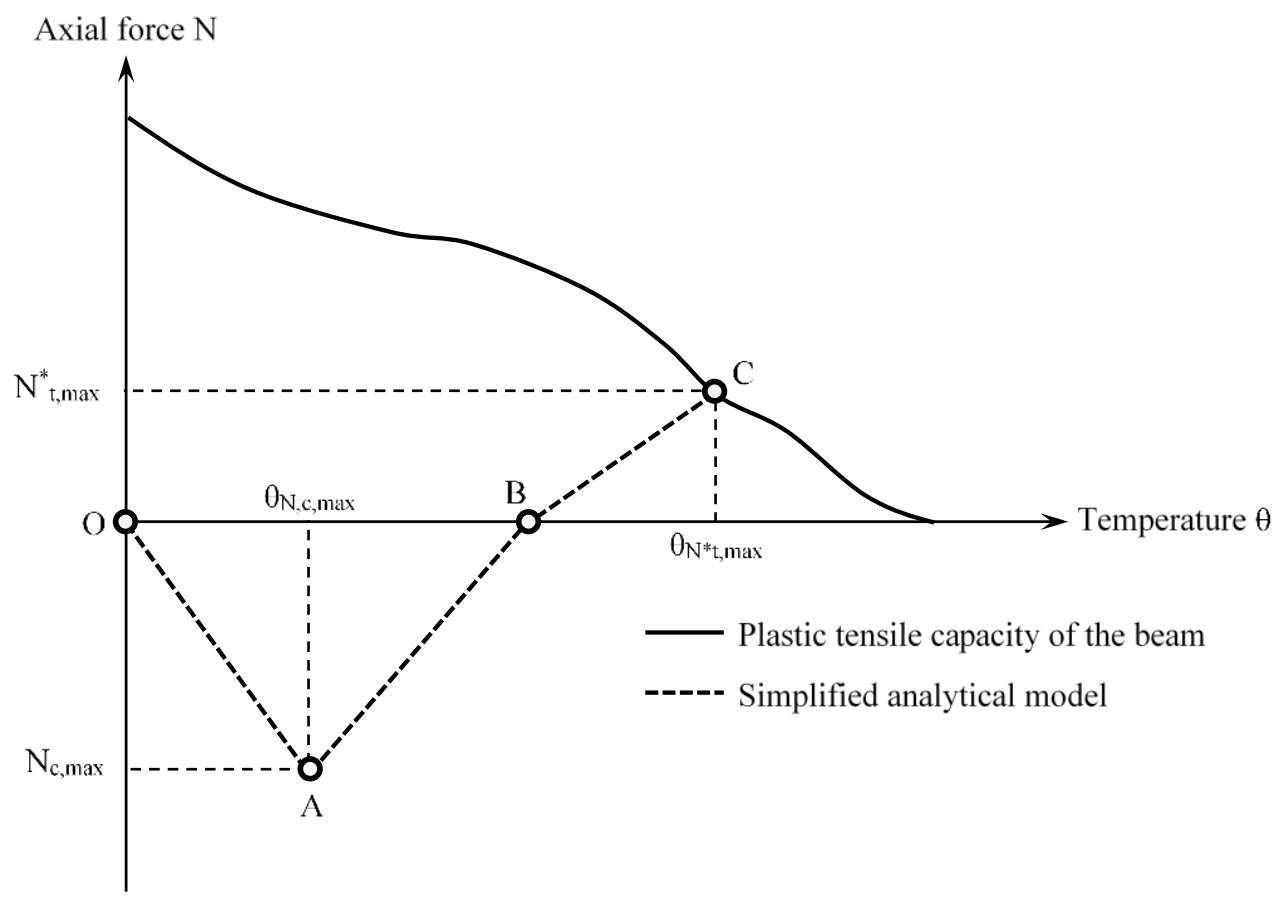

Fig. 15: Schematic representation of the simple analytical solution

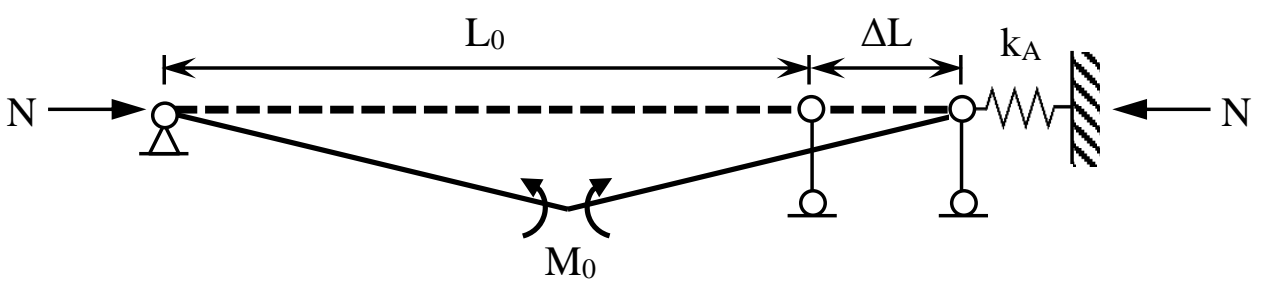

Fig. 16: Axially restrained beam for the development of the simplified analytical model.

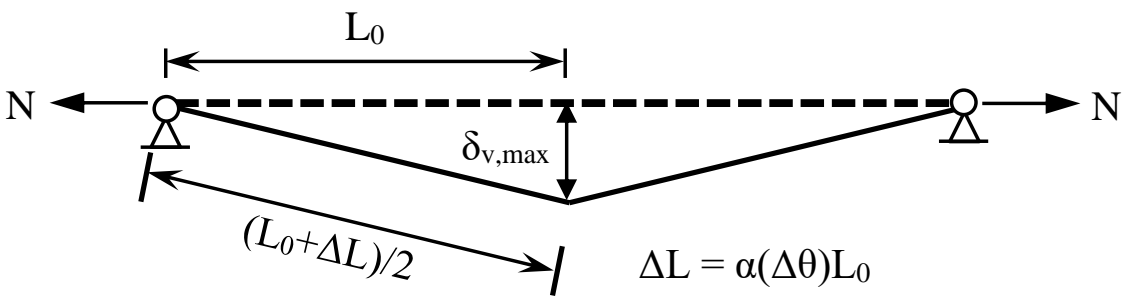

Fig. 17: Deflection model for catenary stage response. 


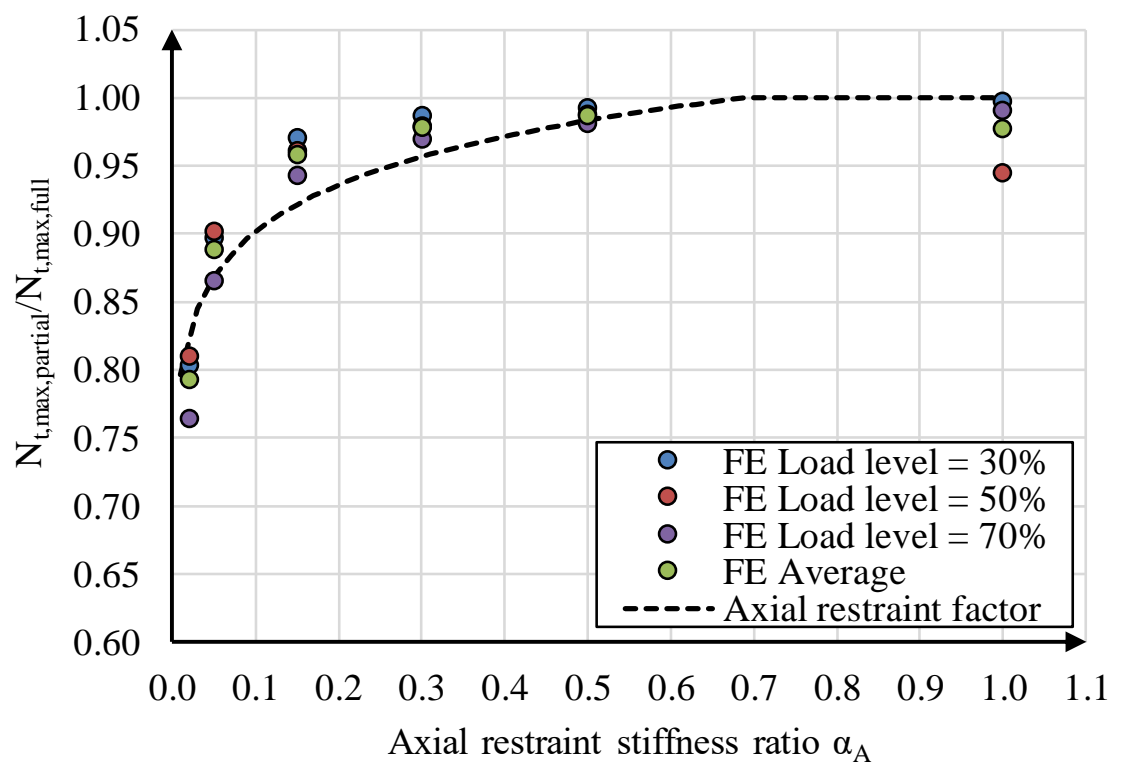

Fig. 18: Variation of the proposed restraint factor $\mathrm{F}_{\alpha \mathrm{A}}$ with axial restraint stiffness ratio $\alpha_{\mathrm{A}}$. 

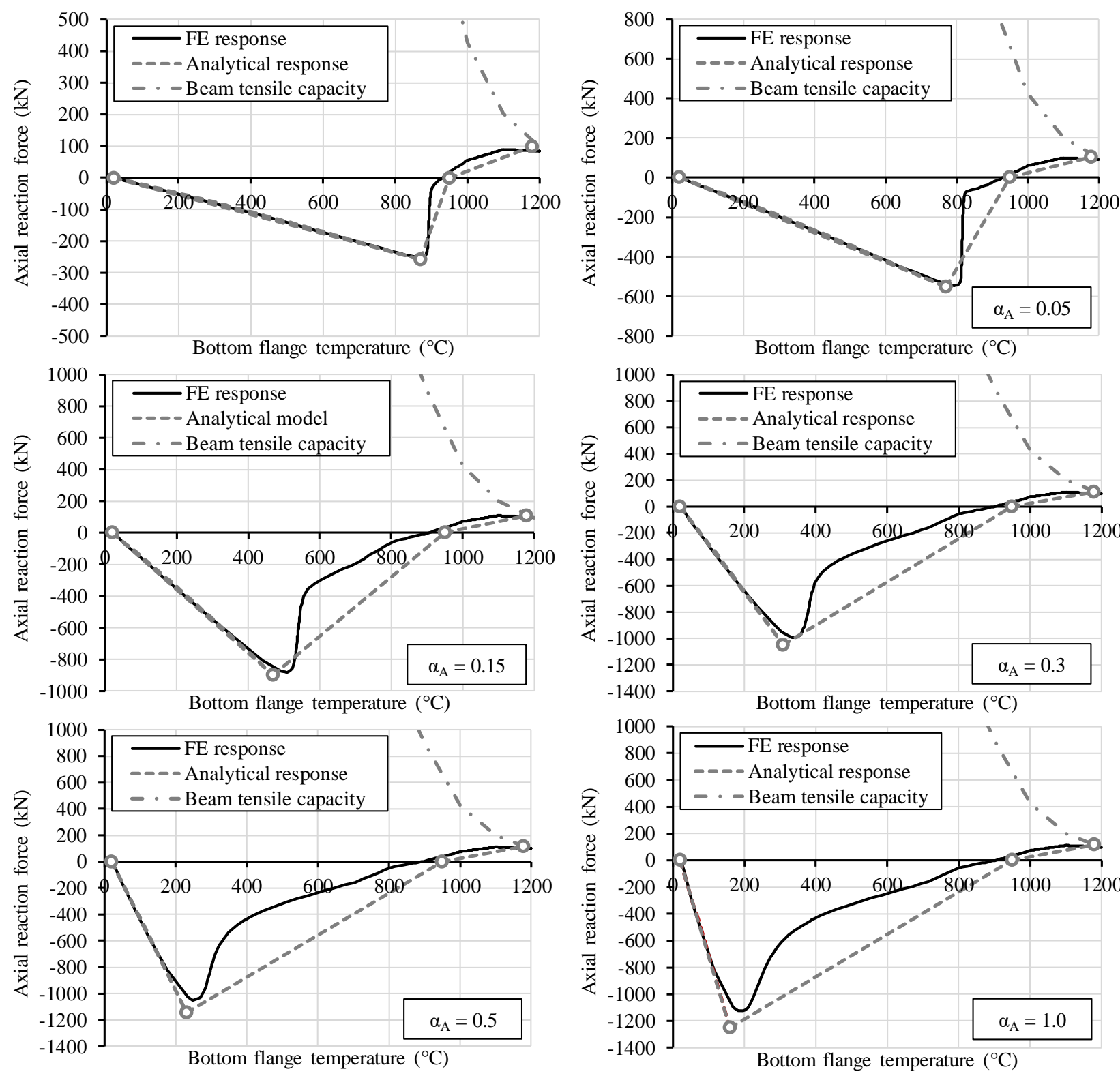

Fig. 19: Comparison of axial force-temperature responses between FE and simple analytical model for beams under $30 \%$ load level. 

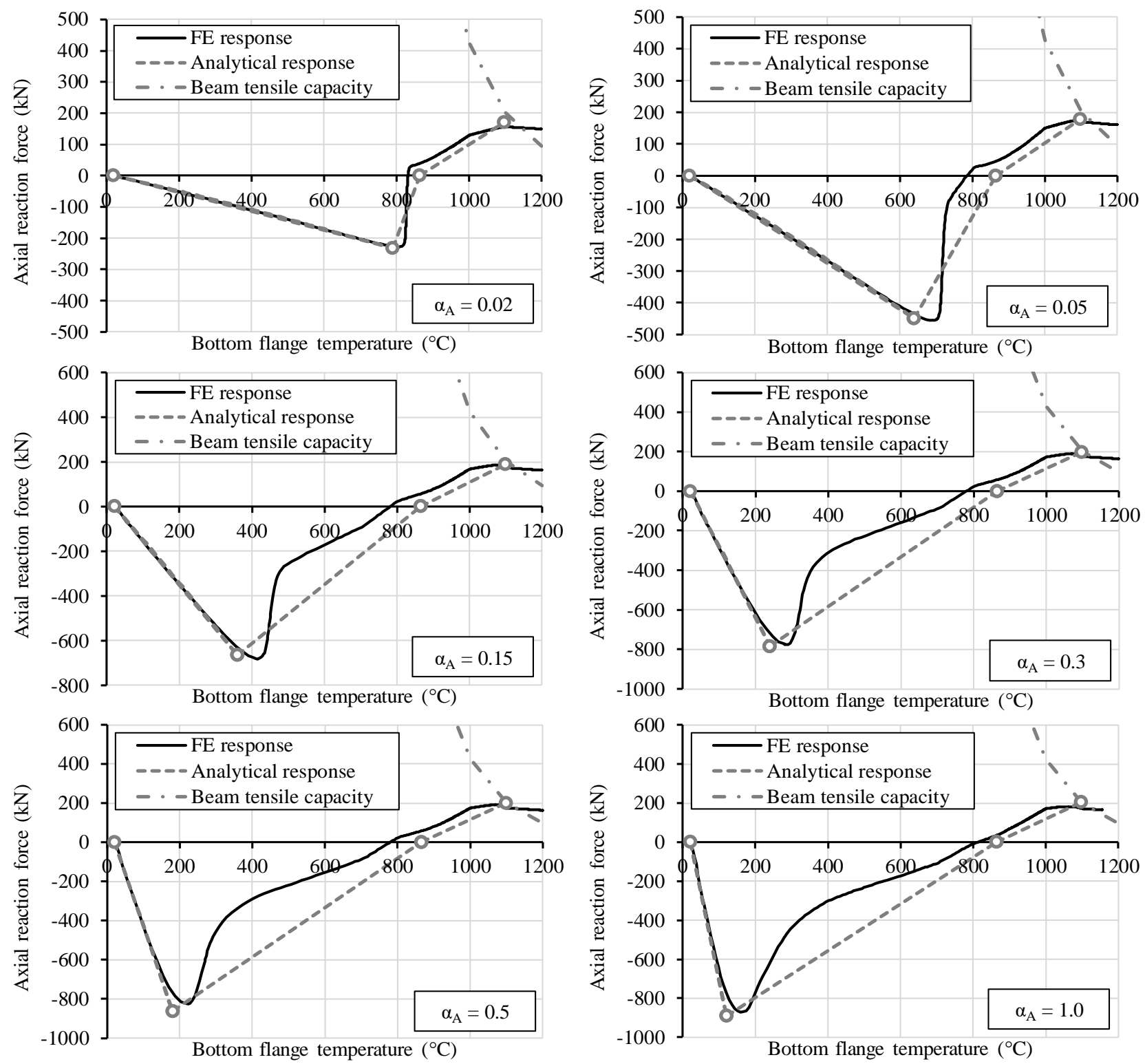

Fig. 20: Comparison of axial force-temperature responses between FE and simple analytical model for beams under $50 \%$ load level. 

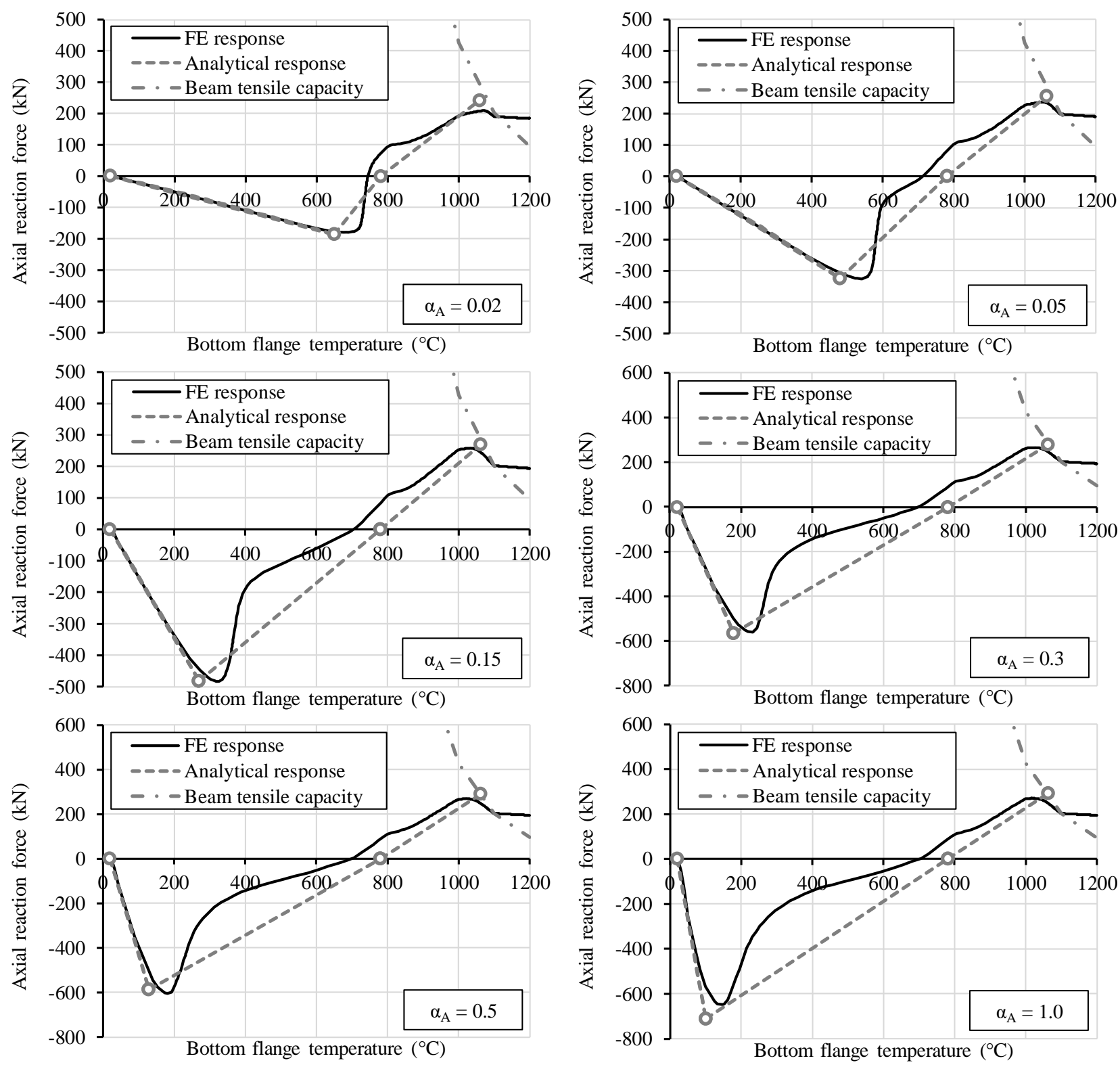

Fig. 21: Comparison of axial force-temperature responses between FE and simple analytical model for beams under $70 \%$ load level. 
Table 1: Summary of the restrained beam tests reported in [11].

\begin{tabular}{l|c|c|c|c|c}
\hline $\begin{array}{l}\text { Specimen } \\
\text { reference }\end{array}$ & Connection type & $\begin{array}{c}\mathrm{k}_{\mathrm{A}} \\
(\mathrm{kN} / \mathrm{mm})\end{array}$ & $\begin{array}{c}\mathrm{k}_{\mathrm{R}} \\
(\mathrm{kNm} / \mathrm{rad})\end{array}$ & $\begin{array}{c}\mathrm{P} \\
(\mathrm{kN})\end{array}$ & $\begin{array}{c}\text { Design load } \\
\text { Level }\end{array}$ \\
\hline FUR09 & Simply supported & 0 & 0 & 40 & 0.5 \\
FUR20 & Simply supported & 0 & 0 & 56 & 0.7 \\
\hline FUR14 & Web cleat & 8 & 0 & 40 & 0.5 \\
FUR16 & Web cleat & 8 & 0 & 56 & 0.7 \\
\hline FUR21 & End plate & 8 & 14000 & 16 & 0.2 \\
FUR13 & End plate & 8 & 14000 & 40 & 0.5 \\
FUR15 & End plate & 8 & 14000 & 56 & 0.7 \\
FUR17 & End plate & 8 & 14000 & 72 & 0.9 \\
\hline FUR27 & End plate & 35 & 14000 & 25 & 0.3 \\
FUR25 & End plate & 35 & 14000 & 40 & 0.5 \\
FUR26 & End plate & 35 & 14000 & 56 & 0.7 \\
\hline FUR32 & Web cleat & 62 & 0 & 40 & 0.5 \\
FUR29 & End plate & 62 & 14000 & 24 & 0.3 \\
FUR31 & End plate & 62 & 14000 & 40 & 0.5 \\
FUR30 & End plate & 62 & 14000 & 56 & 0.7 \\
\hline
\end{tabular}

Table 2: Summary of examined parametric study models.

\begin{tabular}{l|l|l|l}
\hline Beam configuration & Axial restraint condition & $\begin{array}{l}\text { Load level } \\
\text { for stainless } \\
\text { steel beams }\end{array}$ & $\begin{array}{l}\text { Load level } \\
\text { for carbon } \\
\text { steel beams }\end{array}$ \\
\hline \hline No axial restraint & $\begin{array}{l}30 \%, 50 \% \\
\text { and 70\%. }\end{array}$ & $50 \%$ \\
\hline & Full axial restraint & $\begin{array}{l}30 \%, 50 \% \\
\text { and 70\%. }\end{array}$ & $50 \%$ \\
\hline
\end{tabular}


Table 3: Comparison of key results from FE and the simple analytical model responses.

\begin{tabular}{|c|c|c|c|c|c|c|c|c|c|c|c|c|c|c|c|}
\hline \multirow{2}{*}{$\alpha_{\mathrm{A}}$} & \multicolumn{5}{|c|}{ FE } & \multicolumn{5}{|c|}{ Model } & \multicolumn{5}{|c|}{ FE/Model } \\
\hline & $\mathrm{N}_{\mathrm{c}, \max }$ & $\theta_{\mathrm{N}, \mathrm{c}, \max }$ & $\theta_{\mathrm{T}}$ & $\mathrm{N}_{\mathrm{t}, \text { max }}^{*}$ & $\theta_{\mathrm{N} * t, \max }$ & $\mathrm{N}_{\mathrm{c}, \max }$ & $\theta_{\mathrm{N}, \mathrm{c}, \max }$ & $\theta_{\mathrm{T}}$ & $\mathrm{N}_{\mathrm{t}, \text { max }}^{*}$ & $\theta_{N^{*}, \max }$ & $\mathrm{N}_{\mathrm{c}, \max }$ & $\theta_{\mathrm{N}, \mathrm{c}, \max }$ & $\theta_{\mathrm{T}}$ & $\mathrm{N}_{\mathrm{t}, \text { max }}^{*}$ & $\theta_{\mathrm{N}^{*}, \max }$ \\
\hline \multicolumn{16}{|c|}{ Load level = 30\% } \\
\hline 0.02 & 251 & 868 & 928 & 90 & 1101 & 259 & 870 & 950 & 98 & 1179 & 0.97 & 1.00 & 0.98 & 0.92 & 0.93 \\
\hline 0.05 & 545 & 793 & 928 & 100 & 1101 & 553 & 770 & 950 & 103 & 1179 & 0.99 & 1.03 & 0.98 & 0.97 & 0.93 \\
\hline 0.15 & 881 & 507 & 905 & 108 & 1100 & 900 & 470 & 950 & 109 & 1179 & 0.98 & 1.08 & 0.95 & 0.99 & 0.93 \\
\hline 0.30 & 992 & 345 & 897 & 110 & 1101 & 1048 & 310 & 950 & 113 & 1179 & 0.95 & 1.11 & 0.94 & 0.97 & 0.93 \\
\hline 0.50 & 1052 & 248 & 890 & 111 & 1101 & 1143 & 230 & 950 & 116 & 1179 & 0.92 & 1.08 & 0.94 & 0.95 & 0.93 \\
\hline \multirow[t]{3}{*}{1.00} & 1123 & 183 & 901 & 111 & 1101 & 1252 & 160 & 950 & 118 & 1179 & 0.90 & 1.14 & 0.95 & 0.94 & 0.93 \\
\hline & & & & & & & & & & Mean & 0.95 & 1.07 & 0.96 & 0.96 & 0.93 \\
\hline & & & & & & & & & & $\mathrm{COV}$ & 0.04 & 0.05 & 0.02 & 0.03 & - \\
\hline \multicolumn{16}{|c|}{ Load level $=50 \%$} \\
\hline 0.02 & 229 & 803 & 831 & 157 & 1101 & 233 & 790.0 & 865 & 170 & 1098 & 0.98 & 1.02 & 0.96 & 0.92 & 1.00 \\
\hline 0.05 & 455 & 691 & 784 & 174 & 1087 & 450 & 640 & 865 & 178 & 1098 & 1.01 & 1.08 & 0.91 & 0.98 & 0.99 \\
\hline 0.15 & 683 & 417 & 777 & 185 & 1073 & 667 & 360 & 865 & 189 & 1098 & 1.02 & 1.16 & 0.90 & 0.98 & 0.98 \\
\hline 0.30 & 776 & 285 & 775 & 189 & 1069 & 785 & 240 & 865 & 197 & 1098 & 0.99 & 1.19 & 0.90 & 0.96 & 0.97 \\
\hline 0.50 & 825 & 221 & 776 & 191 & 1068 & 864 & 180 & 865 & 202 & 1098 & 0.96 & 1.23 & 0.90 & 0.94 & 0.97 \\
\hline \multirow[t]{3}{*}{1.00} & 870 & 158 & 812 & 182 & 1061 & 890 & 120 & 865 & 205 & 1098 & 0.98 & 1.32 & 0.94 & 0.89 & 0.97 \\
\hline & & & & & & & & & & Mean & 0.99 & 1.16 & 0.92 & 0.95 & 0.98 \\
\hline & & & & & & & & & & $\mathrm{COV}$ & 0.02 & 0.09 & 0.03 & 0.04 & 0.01 \\
\hline \multicolumn{16}{|c|}{ Load level $=70 \%$} \\
\hline 0.02 & 180 & 683 & 743 & 209 & 1069 & 187 & 650 & 781 & 243 & 1059 & 0.97 & 1.05 & 0.95 & 0.86 & 1.01 \\
\hline 0.05 & 325 & 538 & 705 & 237 & 1050 & 325 & 480 & 781 & 255 & 1063 & 1.00 & 1.12 & 0.90 & 0.93 & 0.99 \\
\hline 0.15 & 483 & 325 & 694 & 258 & 1034 & 482 & 270 & 781 & 270 & 1063 & 1.00 & 1.21 & 0.89 & 0.95 & 0.97 \\
\hline 0.30 & 561 & 232 & 689 & 265 & 1026 & 565 & 180 & 781 & 281 & 1063 & 0.99 & 1.29 & 0.88 & 0.95 & 0.97 \\
\hline 0.50 & 606 & 181 & 684 & 268 & 1022 & 589 & 130 & 781 & 288 & 1063 & 1.03 & 1.39 & 0.88 & 0.93 & 0.96 \\
\hline \multirow[t]{5}{*}{1.00} & 648 & 148 & 681 & 271 & 1021 & 710 & 100 & 781 & 293 & 1063 & 0.91 & 1.48 & 0.87 & 0.93 & 0.96 \\
\hline & & & & & & & & & & Mean & 0.98 & 1.26 & 0.90 & 0.92 & 0.98 \\
\hline & & & & & & & & & & $\mathrm{COV}$ & 0.04 & 0.13 & 0.03 & 0.04 & 0.02 \\
\hline & & & & & & & & & & Mean & 0.97 & 1.16 & 0.92 & 0.94 & 0.96 \\
\hline & & & & & & & & & & $\mathrm{COV}$ & 0.04 & 0.11 & 0.04 & 0.04 & 0.03 \\
\hline
\end{tabular}

Note: All loads are in $(\mathrm{kN})$ and all temperatures are in $\left({ }^{\circ} \mathrm{C}\right)$. 